\title{
Morphology of immature stages of Paraegidium costalimai (Coleoptera: Scarabaeidae: Orphninae) and remarks on egg-busters in Scarabaeidae first-instar larvae
}

\author{
Rafael Clayton de Jesus e Sousa ${ }^{1,2}$ \& Juares Fuhrmann ${ }^{1,3}$ \\ 1 Universidade de São Paulo (USP), Museu de Zoologia (MZUSP). São Paulo, SP, Brasil. \\ ${ }^{2}$ ORCID: http://orcid.org/0000-0001-9394-522X. E-mail: rafael.souza1988@gmail.com \\ ${ }^{3}$ ORCID: http://orcid.org/0000-0002-1617-254X. E-mail: jufuhrmann@gmail.com
}

\begin{abstract}
Studies about the immature stages of Orphninae (Coleoptera: Scarabaeidae) species are scarce. The subfamily includes 214 species, but only 5 have the immature stages described: Chaetonyx robustus liguricus Mariani, 1946, Hybalus benoiti Tournier, 1864, H. rotroui Petrovitz, 1964 and Triodontus nitidulus (Guérin, 1844) from Old World; and Aegidium cribratum Bates, 1887 from the New World. The Neotropical genus Paraegidium Vulcano, Pereira \& Martinez, 1966 encompass five species, mainly recorded from Brazil. Herein, the immature stages of P. costalimai Vulcano, Pereira \& Martinez, 1966 are described and illustrated, along with remarks on the presence of egg-buster in Scarabaeidae first-instar larvae. A key to the third-instar larvae of known Orphninae and a comparative study of chaetotaxy are also provided.
\end{abstract}

Key-Words. Aegidiini; Lamellicornia; Pleurosticti; Pupa; White grub.

\section{INTRODUCTION}

Orphninae is a subfamily of Scarabaeidae (Coleoptera) and includes 214 named species (and 1 known species not yet named) distributed in two tribes: Aegidiini and Orphnini. The subfamily occurs in tropical and subtropical regions of the World, except Australia, and is classified in 16 genera (Frolov, 2012; Frolov \& Vaz-de-Mello, 2015; Frolov et al., 2016, 2017a, b; Rojkoff \& Frolov, 2016). The tribe Aegidiini comprises the genera Aegidiellus Paulian, 1984 (Brazil, monotypic), Aegidinus Arrow, 1904 (South America, 10 spp.), Aegidium Westwood, 1845 (South and Central America, Caribbean region, 23 spp.), Onorius Frolov \& Vaz-de-Mello, 2015 (Ecuador, monotypic but with an unnamed known species, Frolov et al., 2019), Paraegidium Vulcano, Pereira, et Martínez, 1966 (South America, 6 spp.), and Stenosternus Karsch, 1881 (Gulf of Guinea: São Tomé Island, monotypic); and the tribe Orphnini includes the genera Chaetonyx Schaum, 1862 (Mediterranean region, 3 spp.), Craniorphnus Kolbe, 1895 (Afrotropical region, monotypic), Goniorphnus Arrow, 1911 (Afrotropical region, monotypic), Hybaloides Quedenfeldt, 1884 (Afrotropical region, monotypic), Hybalus Dejean, 1833 (Mediterranean region, 35 spp.), Madecorphnus Paulian, 1992 (Madagascar, 19 spp.), Orphnus Macleay, 1819 (Afrotropical and Indo-Malayan regions, 92 spp.), Renorphnus Frolov \& Montreuil, 2009 (Madagascar, monotypic), Pseudorphnus Benderitter, 1913 (Madagascar, 4 spp.), and Triodontus Westwood, 1846 (Madagascar, 15 spp.).

The subfamily is distinguished from the other Scarabaeidae by having (Frolov, 2012; Frolov \& Vaz-de-Mello, 2015): mandibles and labrum exposed in dorsal view (hidden by clypeus in Onorius), antennae with 10 antennomeres and 3 lamellae, protibiae of males without spur, anterior area of procoxae with a transversal furrow, dorsal surface of metacoxae with stridulatory striae, spurs of metatibiae separated by tarsal insertion, lateral areas of abdominal sternite II (hidden by metacoxae in ventral view) with a conspicuous sclerotized and pigmented area (plectrum). Sexual dimorphism is usually evident, with males' head and pronotum bearing horns or other ornamentation.

The Neotropical genus Paraegidium was described by Vulcano, Pereira \& Martinez (1966) to include a single species, P. costalimai, from Brazil. 
Recently, Frolov et al. (2017a) revised the genus and described five species mainly recorded in Brazil, with the exception of $P$. howdeni Frolov, Akhmetova \& Vaz-deMello, 2017, from the subandean region of Peru.

Studies about immatures of Orphninae are scarce and only five species have been described so far: Hybalus benoiti Tournier, 1864 and H. rotroui Petrovitz, 1964 (third-instar larva described by Paulian \& Lumaret, 1982), Aegidium cribratum Bates, 1887 (third-instar larva and pupa described by Morón, 1991), Chaetonyx robustus liguricus Mariani, 1946 (third-instar larva described by Barbero \& Palestrini, 1993) and Triodontus nitidulus (Guérin, 1844) (third-instar larva described by Randriamanantsoa et al., 2011).

Gradinarov \& Petrova (2012), Gradinarov (2014) and Gradinarov et al. (2015) studied the biology of Orphninae from Bulgaria and provided notes on the habitat preferences and life cycle of Chaetonyx robustus Schaum, 1862 and included some measurements and photographs of immatures of this species. Even though 3 subspecies for C. robustus are known (the nominotypical subspecies, H. robustus italicus Mariani, 1946, and H. robustus liguricus Mariani, 1946), the above-mentioned authors did not use the subspecific classification and noted that it is doubtful.

The purpose of the present study is I) to describe the immature stages of Paraegidium costalimai, II) to discuss the egg-busters of first-instar larvae, and III) clarify the classification of immature stages of Orphninae.

\section{MATERIAL AND METHODS}

Larvae of $P$. costalimai were collected at two urban parks in São Paulo (state of São Paulo, SP): Instituto Biológico de São Paulo (IBSP) and Parque da Independência, both with a secondary woodland cover (Fig. 1). Larvae were found at $10 \mathrm{~cm}$ depth in the soil.

The reared adult was identified in comparison with paratypes of $P$. costalimai (MZSP) and following Frolov et al. (2017a).

Immatures were killed in boiling water and preserved in $70 \%$ alcohol. Observations and drawings were carried out in a Zeiss Stemi SV6 stereomicroscope or Zeiss Axioscop microscope, both with a coupled light camera. Detached larval structures (e.g., mouthparts and legs) were provisionally mounted on glycerin jelly slides (see Burrows, 1965; Johansen, 1940; Perina \& Camacho, 2016; Widden, 2001).

Photographs were taken with a Canon EOS 80D DSLR Camera with a Canon MP-E $65 \mathrm{~mm}$ f/2.8 lens and an LED illumination system (Kawada \& Buffington, 2016). For small dissected a Lucky Zoom USB eyepiece camera attached to a microscope was used. Images were processed using Zerene stacker. The Adobe Photoshop CC 2018 software was used for image processing. Measurements were taken in millimeters using a micrometer.

The terminology used followed Böving (1936) and Lawrence (1991) with modifications by Sousa et al. (2018). Head chaetotaxy followed Ritcher (1966) and
Sawada (1991), as summarized by Sousa et al. (2018). Lobes of thorax and abdomen followed Rodrigues et al. (2018). The hair-like setae were separated into the two well-defined groups: minute setae and short-long setae (modification of Šípek et al., 2008; see Rodrigues et al., 2018). The term phobae was used by Böving (1936) to the fleshy projections, even though in P. costalimai it is stiff and slightly sclerotized.

\section{RESULTS}

\section{Paraegidium costalimai Vulcano, Pereira \& Martinez, 1966} (Figs. 2-74)

Material examined: Brazil. Pará: Cachimbo, x.1955, Padre Pereira (collector), 1 \% adult, x.1959, M. Alvarenga (collector), $3 \%$ and $3 \sigma^{7}$ adults (paratypes). Rio de Janeiro: Itatiaia, $1 \sigma^{\prime}$ adult (paratype), xii.1949, W. Zikán (collector), $2 \%$ and $1 \sigma^{\prime}$ adults (paratypes), 07.xii.1951, W. Zikán (collector), 1 \% adult (paratype), Rio de Janeiro, Corcovado, xi.1959, M. Alvarenga (collector), $1 \sigma^{7}$ adult (paratype). São Paulo: São Paulo, Cantareira, ii.1937, 1 q adult (paratype), Ipiranga, xii.1993, Sérgio Ide (collector), 1 \% adult,

Table 1. Chaetotaxy of the known third instars of Orphninae.

\begin{tabular}{|c|c|c|c|c|c|c|c|}
\hline & Sp. & 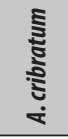 & 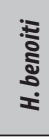 & ث. & 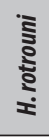 & 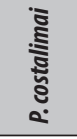 & 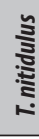 \\
\hline \multirow{4}{*}{ parietals } & des & 2 & 3 & 2 & 4 & 2 & 3 \\
\hline & pes & 1 & 2 & $2-3$ & 2 & $2-3$ & - \\
\hline & aes & 1 & 1 & 1 & 1 & 1 & - \\
\hline & ees & 3 & 4 & 4 & 4 & $4-5$ & 5 \\
\hline \multirow{4}{*}{ frons } & pfs & 0 & 0 & 0 & 0 & 0 & - \\
\hline & efs & 1 & 1 & 0 & 1 & 1 & - \\
\hline & aas & 0 & 1 & 1 & 1 & 1 & 1 \\
\hline & afs & 1 & - & 0 & - & 1 & 一 \\
\hline \multirow{2}{*}{ clypeus } & acs & 1 & 1 & 1 & 1 & 1 & 1 \\
\hline & ecs & 2 & 2 & 1 & 1 & 2 & 1 \\
\hline \multirow{4}{*}{ labrum } & pls & 2 & 4 & 2 & 4 & 2 & 2 \\
\hline & Ils & 2 & 3 & 2 & 3 & 3 & 2 \\
\hline & $\mathrm{mls}$ & 2 & 2 & 2 & 2 & 2 & 2 \\
\hline & als & 2 & 1 & 1 & 1 & 2 & 2 \\
\hline \multirow{4}{*}{ raster } & $\operatorname{tg}$ & 18 & - & - & - & $78-82$ & 36 \\
\hline & pr & 8 & - & - & - & $24-31$ & 12 \\
\hline & pa & $19-23$ & - & - & - & - & 20 \\
\hline & al & 0 & 0 & 0 & 0 & 0 & 0 \\
\hline
\end{tabular}

The chaetotaxy is given for one side of the structure, except for ventral anal lobe (al). = about; - = setae not quantified or figured by studies.

Raster and anal lobe: only hamate setae quantified, when hamate setae absent the number of hair-like setae is given between square brackets.

Preseptular setae (pr): tegillar setae anterior to palidia-septula. $\mathbf{u}=$ unapplied (i.e., when palidia-septula are absent, it is impossible define the preseptular setae).

Setae group: aas = anterofrontal angle setae; acs = anteroclypeal setae; aes = anteroepicrania setae; afs = anterofrontal setae; al = ventral anal lobe setae; als = anterolabral setae; des = dorsoepicranial setae; lls = laterolabral setae; $\mathbf{m l s}=$ mediolabral setae; ecs = externoclypeal setae; ees = externoepicranial setae; efs = externofrontal setae; $\mathbf{p a}=$ palidium setae (pali); pes $=$ posteroepicranial setae; $\mathbf{p f s}=$ posterofrontal setae; $\mathbf{p l s}=$ posterolabral setae; $\mathbf{p r}=$ tegillar preseptular setae; $\mathbf{t g}=$ tegillar setae (including $\mathbf{~ p r}$ ). 
22.i.1997, S. Ide (collector), 1 adult, x.2001-i.2002, 2 잉 and $2 \sigma^{x}$ adults, Parque do Instituto Biológico, 02.x.2011, J. Fuhrmann \& D.C. Bená (collectors), 1 ơ pupa (MZSP 10366); 09.x.2011, J. Fuhrmann (collector), 1 \& pupa (MZSP 10367), Parque da Independência, 25.vii.2018, J. Fuhrmann, R. Sousa, B. Zilberman \& L. Migliori (collectors), 1 first-instar larva, 6 third-instar larvae, 19 reared to adult (MZSP 10364).
Third-instar larva (Figs. 5-55, 73-74): Body posteriorly enlarged (Fig. 5), white, head and respiratory plates yellow, mandibles darker and body setae yellowish brown. Head (Figs. 6-7, setation in Table 1) width about $2.2 \mathrm{~mm}$, epicranial and epistomal sutures distinct, stemmata absent, antennifer somewhat cylindrical and with 2 punctures, cranium with homogeneously distributed punctures, and each side of clypeus with 5 punctures. Each
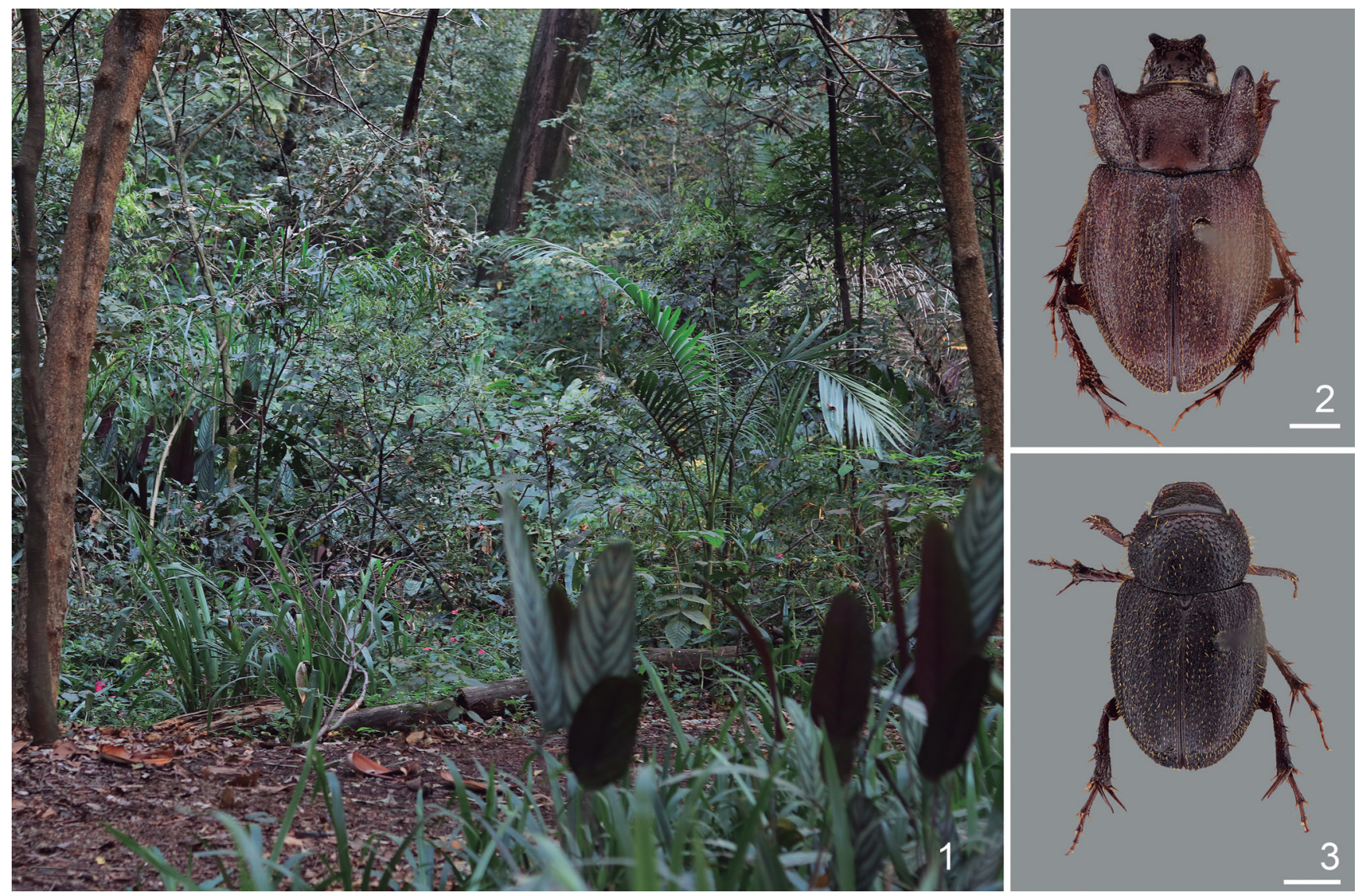

Figures 1-3. Paraegidium costalimaiVulcano, Pereira \& Martinez, 1966. (1) Collect site at the Parque da Independência (São Paulo, Brazil); (2) Male, adult; (3) Female, adult. Scale $=1 \mathrm{~mm}$.

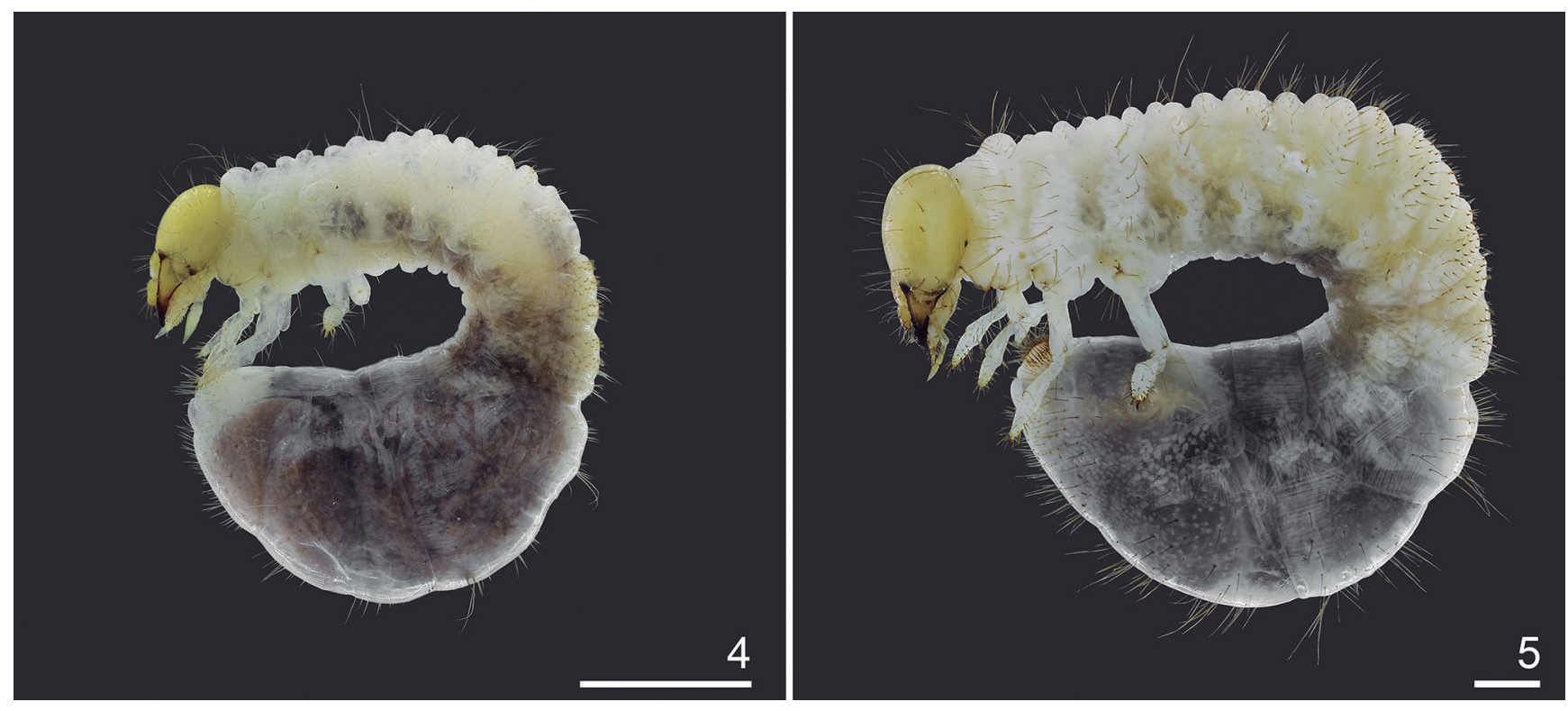

Figures 4-5. Larvae of Paraegidium costalimai Vulcano, Pereira \& Martinez, 1966. Habitus lateral: (4) First instar. (5) Third instar. Scale = 1 mm. 


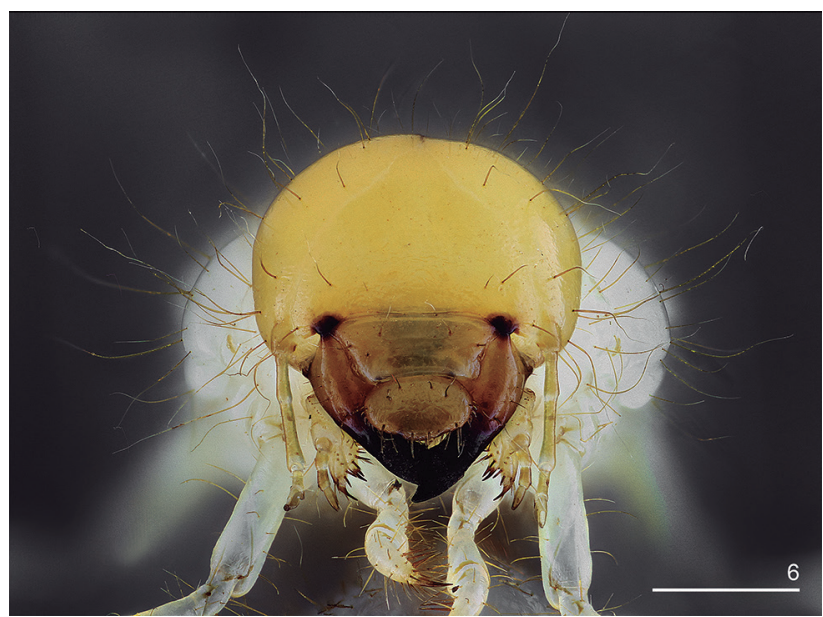

Figure 6. Paraegidium costalimai Vulcano, Pereira \& Martinez, 1966. Thirdinstar larva: head, dorsal. Scale $=1 \mathrm{~mm}$. side of cranium and clypeus with (Figs. 6, 12): 2 dorsoepicranial setae (des), 2-3 posteroepicranial setae (pes), 1 anteroepicranial seta (aes), 4-5 externoepicranial setae (ees), posterofrontal setae (pfs) absent, 1 externofrontal seta (efs), 1 anterofrontal angle seta (aas), 1 anterofrontal seta (afs), 2 externoclypeal setae (ecs), and 1 anteroclypeal seta (acs). Each side of labrum (Figs. 13-14) with 7 sensilla (3 posterior, 2 lateral, 1 anterior), 2 long posterolabral setae $(\mathrm{p} / \mathrm{s}), 2$ mediolabral setae $(\mathrm{m} / \mathrm{s}), 3$ laterolabral setae (I/s), and 1 long and 1 short anterolabral setae (als). Antenna (Figs. 8-11, 16) with 4 antennomeres: I with 1 dorsal sensillum; Il with 7 sensilla ( 3 dorsal, 1 inner, 1 outer, 2 ventral); III with 7 sensilla ( 3 dorsal, 2 inner, 2 ventral), ventrodistal process bearing a dorsal sensorial spot and 3 sensilla ( 2 distal, 1 proximal); IV with 3 sensilla ( 2 dorsal, 1 ventral), 1 dorsal and 1 ventral sensorial spots, and a distal sensorial area bearing about 8 minute sensilla.
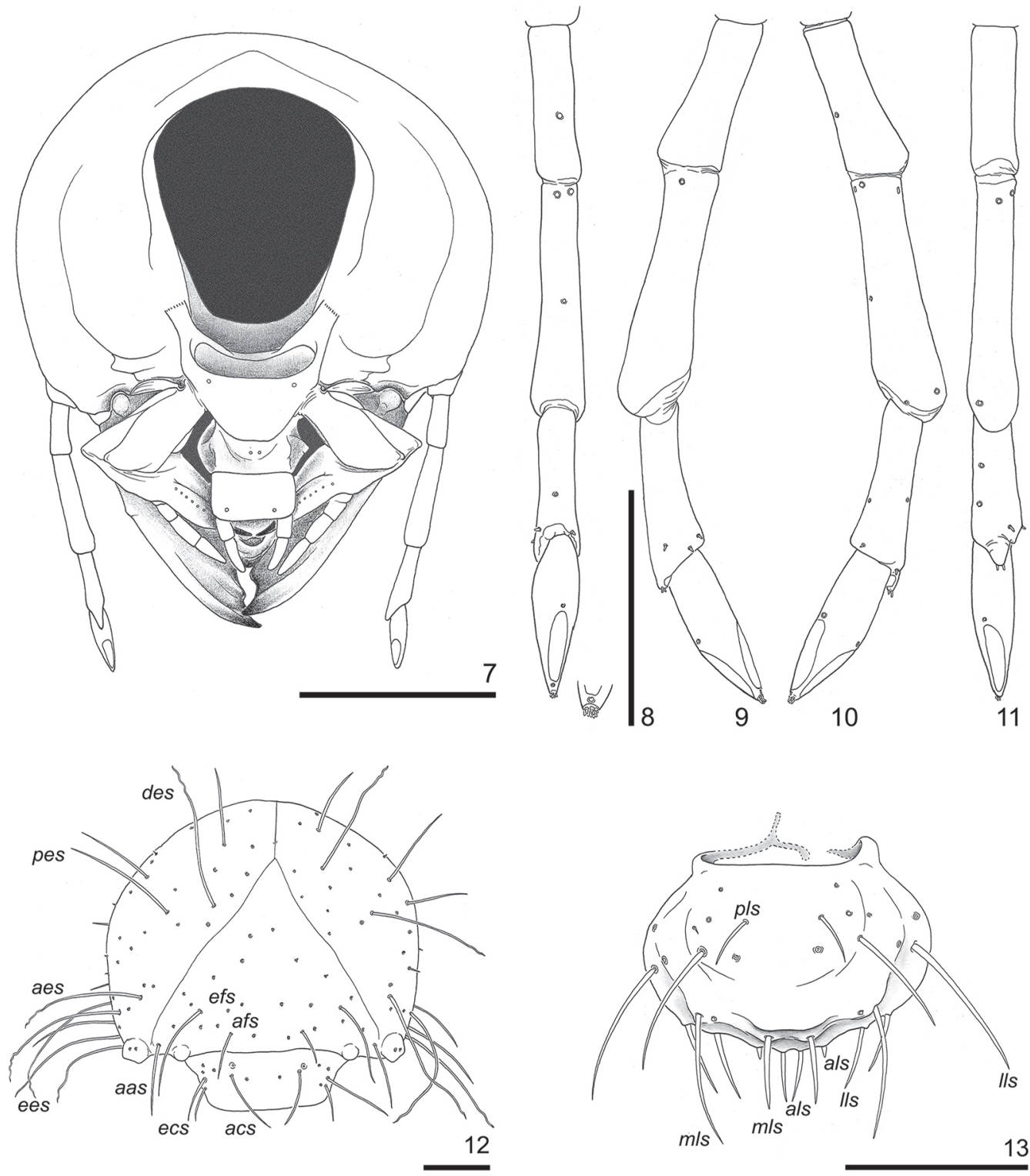

Figures 7-13. Paraegidium costalimai Vulcano, Pereira \& Martinez, 1966. Third-instar larva: (7) Head, ventral; (8-11) Left antenna (dorsal, inner, outer, ventral); (12) Cranium and clypeus; (13) Labrum. aas = anterofrontal angle setae; acs = anteroclypeal setae; aes = anteroepicranial setae; afs = anterofrontal setae; als = anterolabral setae; $\mathbf{d e s}=$ dorsoepicranial setae; $\mathbf{l l} \mathbf{s}=$ laterolabral setae; $\mathbf{m l} \mathbf{s}=$ mediolabral setae; $\mathbf{e c s}=$ externoclypeal setae; ees = externoepicranial setae; $\mathbf{e f s}=$ externofrontal setae; pes $=$ posteroepicranial setae; $\mathbf{p f s}=$ posterofrontal setae; $\mathbf{p l s}=$ posterolabral setae. Scale: Fig. $7=1 \mathrm{~mm}$, Figs. $8-13=0.5 \mathrm{~mm}$ (antennal details with magnification two times bigger than antennae). 


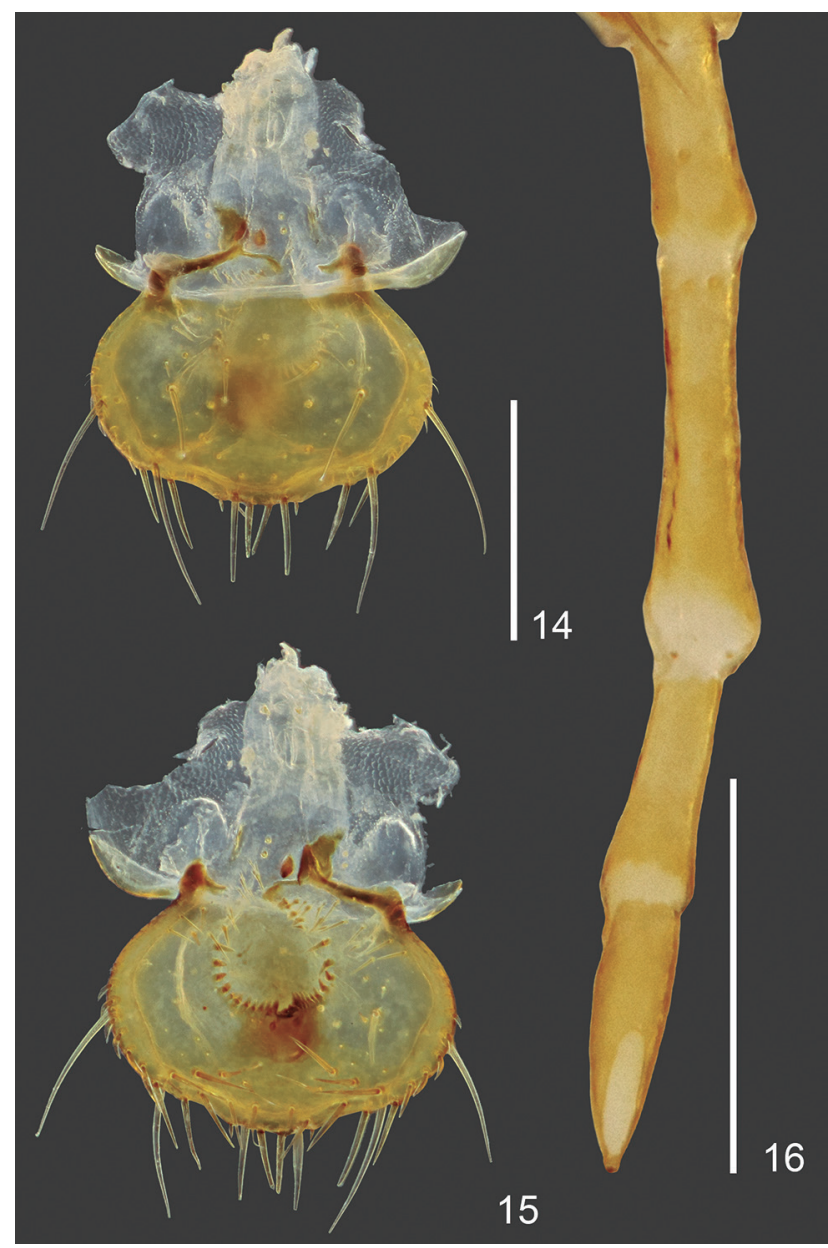

Figures 14-16. Paraegidium costalimai Vulcano, Pereira \& Martinez, 1966. Third-instarlarva: (14) Labrum; (15) Epipharynx; (16) Antenna. Scale =0.5 mm.
Table 2. Thorax and abdomen chaetotaxy of Paraegidium costalimai.

\begin{tabular}{|c|c|c|c|c|c|c|c|c|c|c|c|}
\hline & sgs & t1 & t2 & t3 & a1-2 & a3 & a4-5 & a6 & a7 & a8 & a9 \\
\hline \multirow{5}{*}{$\begin{array}{l}\text { Dorsal } \\
\text { Lobes }\end{array}$} & $\mathbf{t l}^{*}$ & $78-84$ & $\mathrm{u}$ & u & u & $\mathrm{u}$ & $\mathrm{u}$ & u & $62-64$ & $54-56$ & $42-58$ \\
\hline & tal & $\mathrm{u}$ & $4-5$ & $=$ & $6-10$ & $12-16$ & $\begin{array}{c}2-5 \\
{[15]}\end{array}$ & $=$ & u & u & u \\
\hline & $\mathrm{tml}$ & u & 29-34 & $=$ & $16-30$ & $41-44$ & $\begin{array}{c}21-26 \\
{[28-29]}\end{array}$ & $=$ & u & u & $\mathrm{u}$ \\
\hline & tpl & u & $7-8$ & $=$ & $14-20$ & $\begin{array}{c}11-15 \\
{[11-14]}\end{array}$ & $\begin{array}{c}2-4 \\
{[25-26]}\end{array}$ & $19-20$ & u & u & u \\
\hline & ts & $\#$ & $\mathrm{u}$ & u & u & u & $\mathrm{u}$ & u & u & u & u \\
\hline \multirow{5}{*}{$\begin{array}{l}\text { Dorsolateral } \\
\text { Lobes }\end{array}$} & $\mathbf{p l}^{*}$ & $1-2$ & 3 & u & $1-4$ & $=$ & $=$ & $=$ & $=$ & $=$ & $6-9$ \\
\hline & pal & u & $\mathrm{u}$ & 1 & u & u & $\mathrm{u}$ & u & u & $\mathrm{u}$ & u \\
\hline & ppl & u & u & 1 & u & u & u & u & u & u & $\mathrm{u}$ \\
\hline & esl & u & u & u & $3-5$ & $=$ & $=$ & $=$ & $=$ & $1-2$ & u \\
\hline & tll & $\mathrm{u}$ & $\mathrm{u}$ & u & u & u & $1-2$ & $=$ & $0-1$ & $\mathrm{u}$ & $\mathrm{u}$ \\
\hline \multirow{4}{*}{$\begin{array}{l}\text { Ventral } \\
\text { Lobes }\end{array}$} & $\mathbf{v} \mathbf{l}^{*}$ & $6-8$ & $\mathrm{u}$ & u & u & u & u & u & u & 4 & $=$ \\
\hline & val & u & $7-8$ & $=$ & $8-10$ & $=$ & $4-6$ & $=$ & $=$ & u & u \\
\hline & vml & u & u & u & u & u & u & u & u & u & $\mathrm{u}$ \\
\hline & vpl & u & 0 & $=$ & $=$ & $=$ & $=$ & $=$ & $=$ & $\mathrm{u}$ & $\mathrm{u}$ \\
\hline
\end{tabular}

The chaetotaxy is given for the entire lobe, main interval related to thin setae, stout setae between square brackets.

* $=$ When segment lobes (sgs) are undivided, the general lobe $(\mathbf{t l}, \mathbf{p l}, \mathbf{v l})$ chaetotaxy is given. $==$ similar to immediately anterior segment; $\mathbf{u}=$ unapplied (when lobe is indistinct); \# = thoracic tergal sclerite is barely distinct in P. costalimai and setae of the region are quantified as part of tergal lobe $(\mathbf{t l})$.

Segments: $\mathbf{t 1 - 3}=$ pro-, meso- and metathorax; $\mathbf{a} 1-9=$ abdominal segment $1-I X$.

Dorsal lobes: $\mathbf{t a l}=$ tergal anterior lobe; $\mathbf{t} \mathbf{l}=$ tergal lobe; $\mathbf{t m l}=$ tergal medial lobe; $\mathbf{t p l}=$ tergal posterior lobe; $\mathbf{t s}=$ tergal sclerite of prothorax.

Dorsolateral lobes: $\mathbf{e s} \mathbf{I}=$ spiracular lobe; $\mathbf{p l a}=$ pleural anterior lobe; $\mathbf{p p l}=$ pleural posterior lobe; $\mathbf{t l l}=$ tergal lateral lobe.

Ventral lobes: val = ventral anterior lobe; $\mathbf{v l}=$ ventral lobe; $\mathbf{v m l}=$ ventral medial lobe; $\mathbf{v p l}=$ ventral posterior lobe.

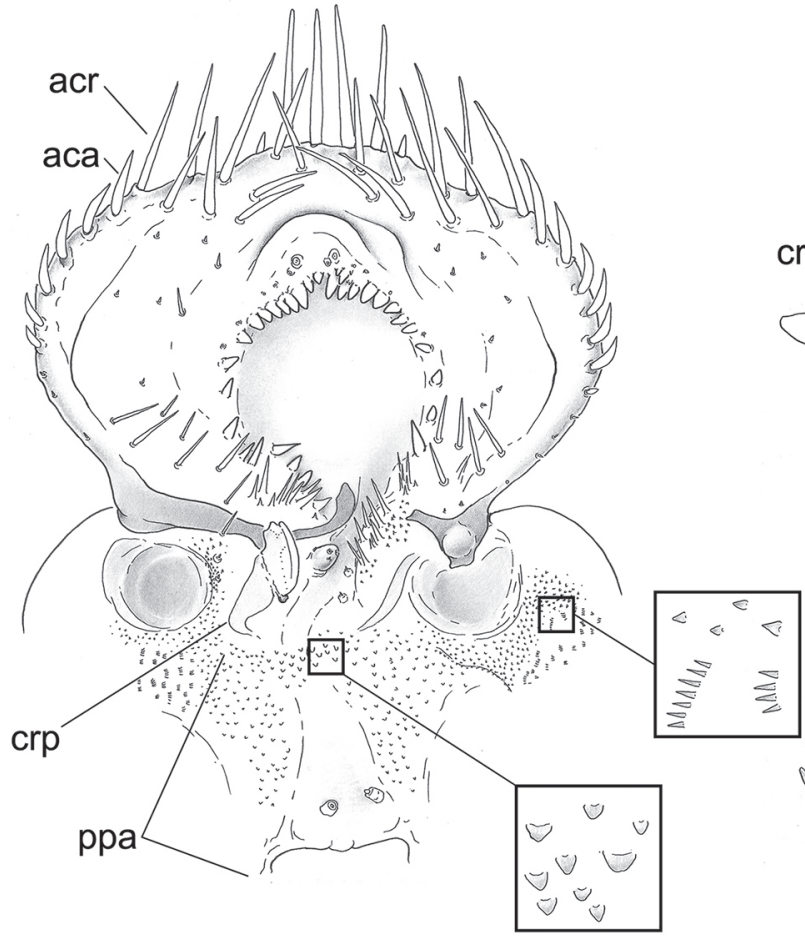

17

Figures 17-18. Paraegidium costalimaiVulcano, Pereira \& Martinez, 1966. Third-instar larva: (17) Epipharynx; (18) Cibarium, lateral. aca = acanthoparia; acr = acroparia; $\mathbf{c r p}=$ crepis; ppa $=$ posterior preoral area. Scale $=0.3 \mathrm{~mm}$ (asperites details with magnification eight times bigger than the epipharynx and posterior preoral area). 
Epipharynx (Figs. 15, 17-18). Corypha with epizygum and clithra indistinct. Haptomerum prominent, sclerotized, with 2 sensilla on each side, zygum indistinct. Paria with acroparia evidently separated from chaetoparia, each side of acroparia with 8 setae, right and left acanthoparia with 6-7 anterior setae and 3-4 minute posterior setae, gymnoparia wide, right and left chaetoparia with about 7 minute or short setae and 5-7 posterior long setae. Dexiotorma four times longer than laeotorma, left pterotorma rounded, apotorma indistinct, epitorma three times longer than laeotorma and contiguous to dexiotorma. Plegmatia and proplegmatia absent, and right and left spiny phobae present. Pedium circular and surrounded by about 30 heli and 8 minute sensilla.
Haptolachus with right area bearing a seta and 2 sensilla, left area bearing 2 sensilla; nesium internum (sensorial cone) tubercle-like and with 3 sensilla; nesium externum (sclerotized plate) prominent and blade-like; crepis lateral area conspicuous and medial area indistinct. Mandible (Figs. 19-30). Incisor with 2 well-defined teeth (S2 inconspicuous), dorsoproximal area with 2 punctures and a seta. Ventral area with posterior asperites. Scrobe (outer proximal area) with about 4 setae and $4-5$ sensilla. Ventral processes with 3-4 ventroproximal sensilla. Each molar with about 4 dorsoproximal setae in a row and about 6 ventroproximal setae in a tuft; right brustia 5 stout setae and left brustia with 7 dorsal stout setae and 10 ventral thin setae; right molar with 2 chisel-like teeth and calx
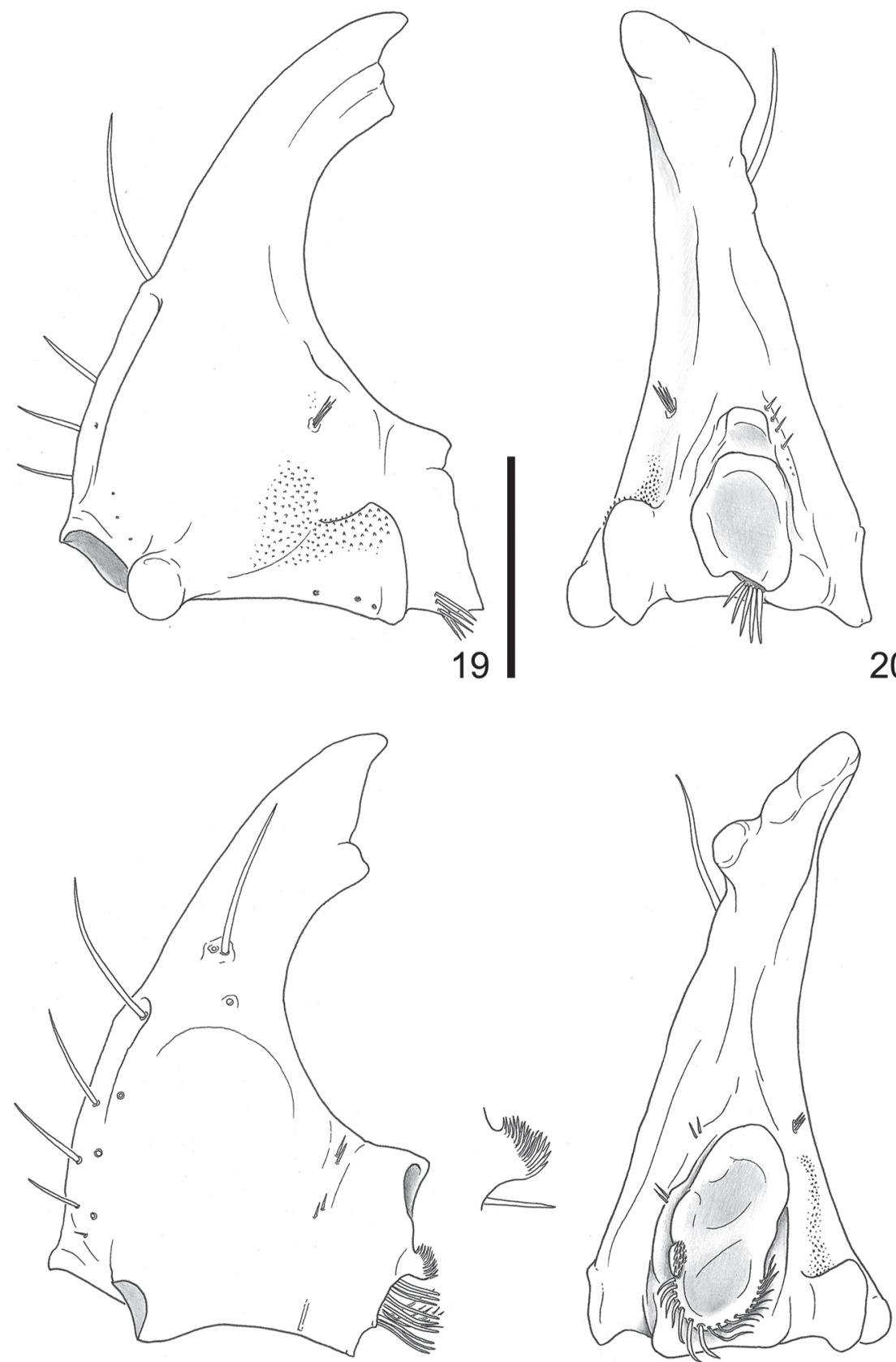

22

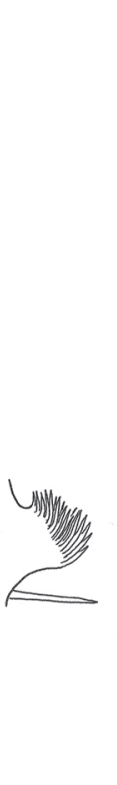

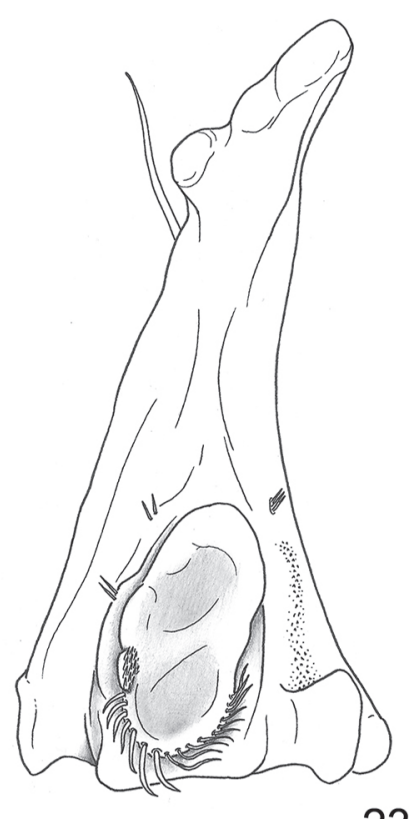

23

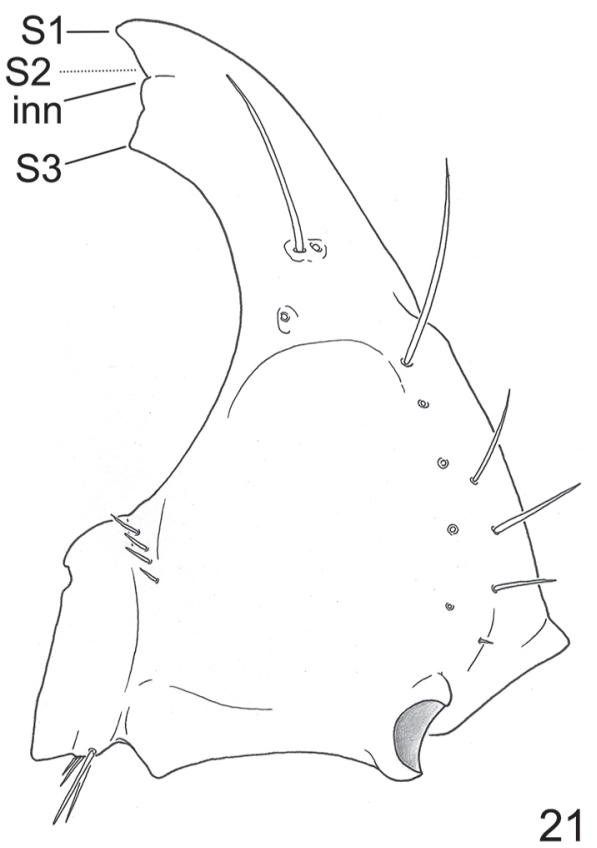

21

Figures 19-24. Paraegidium costalimai Vulcano, Pereira \& Martinez, 1966. Third-instar larva: (19-21) right mandible (ventral, inner, dorsal); (22-24) left mandibles (dorsal, inner ventral). S1-3 = distal, medial and proximal teeth of incisor, medial tooth barely distinct; inn = incisor notch (between S2 and S3). Scale $=0.5 \mathrm{~mm}$ (acia details with magnification two times bigger than the mandible). 
slightly sinuous; left molar with an anterior chisel-like tooth, acia with apex obliquely truncate and bearing a dense group of thin spines (Fig. 22 detail), calyx semicircular. Maxilla (Figs. 31-35). Galea and lacinia separate; galea with an uncus and a row of 6 ventral setae; lacinia with 2 unci, each uncus with a proximal seta. Stipes with stridulatory area bearing 12-15 acute teeth. Palpus with 4 palpomeres: I small; II with 3 sensilla (2 dorsal, 1 ventral); III with an outer seta, a ventral seta, and 2 ventral sensilla; IV with 2 sensilla (1 inner, 1 outer), distal sensorial area bearing about 13 sensilla. Hypopharynx (Figs. 18, 32, 34) with asymmetrical sclerite, each lateral lobe with 4-6 setae; left lateral lobe with a spiny phoba bearing about 13 projections, some projections bifurcate; right area with a prominent anterior tooth and 4-6 posterior heli. Posterior preoral area (Fig. 18): each side of dorsal area (posterior to epipharynx, Fig. 17) with a sensillum and an anterior concavity; each side of the ventral area (posteri- or to hypopharynx, Fig. 32) with 2-3 sensilla. Labium (Figs. 18, 32-33). Submentum with an inconspicuous sclerite, each side with a seta and a sensillum. Mentum with a transversal sclerite, each side with a seta and 3 sensilla. Prementum with a transversal sclerite, each side with a posteromedial short seta, 3 distal setae, and 2 sensilla (1 medial, 1 distal); ligula (Figs. 18, 32, 34) rectangular, each side with about 24 setae ( 9 posterolateral, 15 anterolateral) and 4 sensilla ( 2 anterior, 2 medial), posterior area without asperites. Palp with 2 palpomeres: I with a minute ventroproximal seta and an inner sensillum; II with a ventrodistal sensillum, distal sensorial area with about 13 sensilla (Fig. 32 detail). Thorax (Fig. 5, for setation refer to Table 2) with tergal sclerite thin and barely distinct. Prothorax with tergal lobe bearing 78-84 setae, pleural lobe with 1-2 setae, and ventral lobe with 6-8 setae. Mesothorax with tergal anterior lobe bearing 4-5 setae, tergal medial lobe with 29-34 setae, tergal posterior

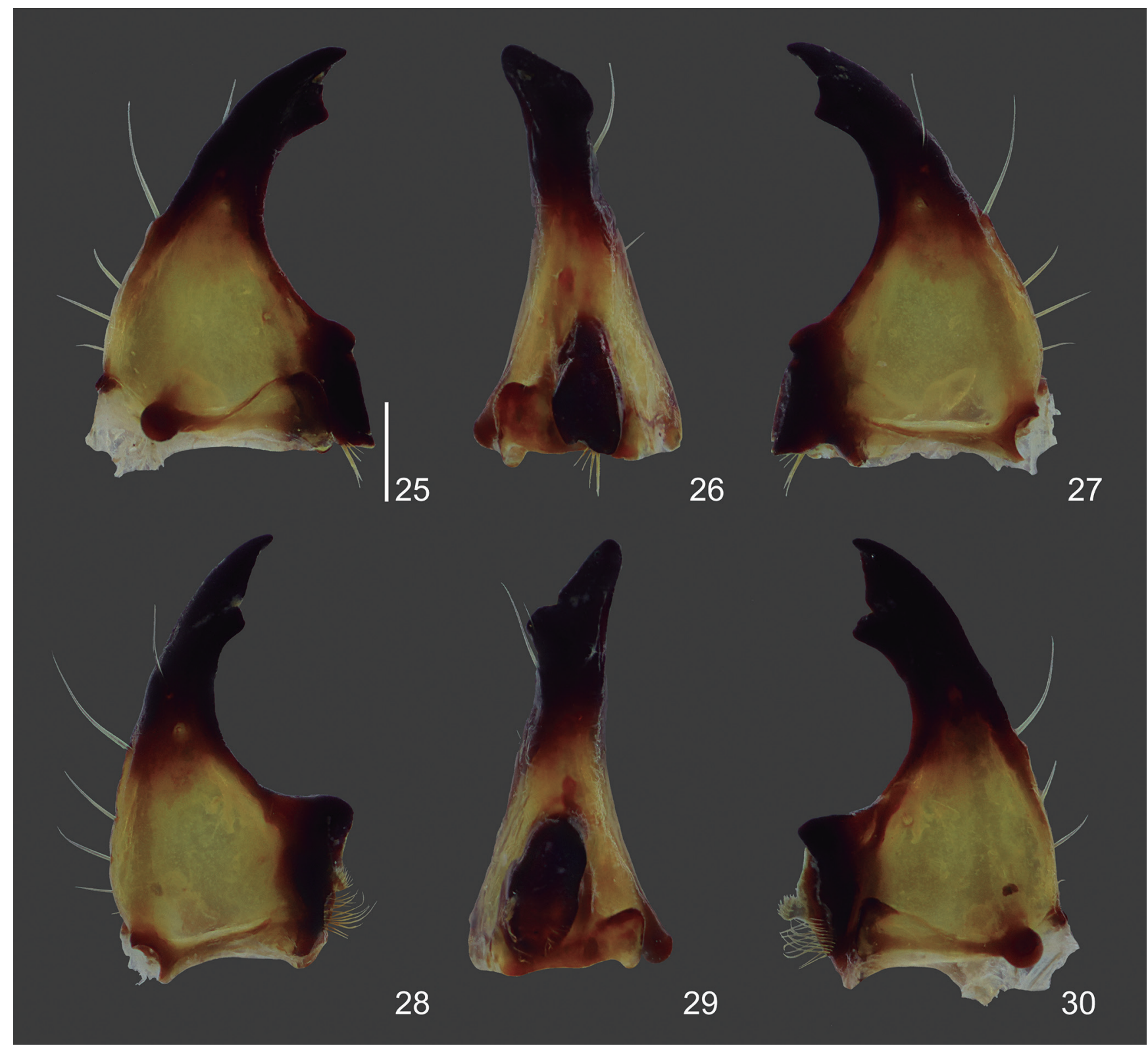

Figures 25-30. Paraegidium costalimai Vulcano, Pereira \& Martinez, 1966. Third-instar larva: (25-27) right mandible (ventral, inner, dorsal); (28-30) left mandibles (dorsal, inner ventral). Scale $=0.25 \mathrm{~mm}$. 


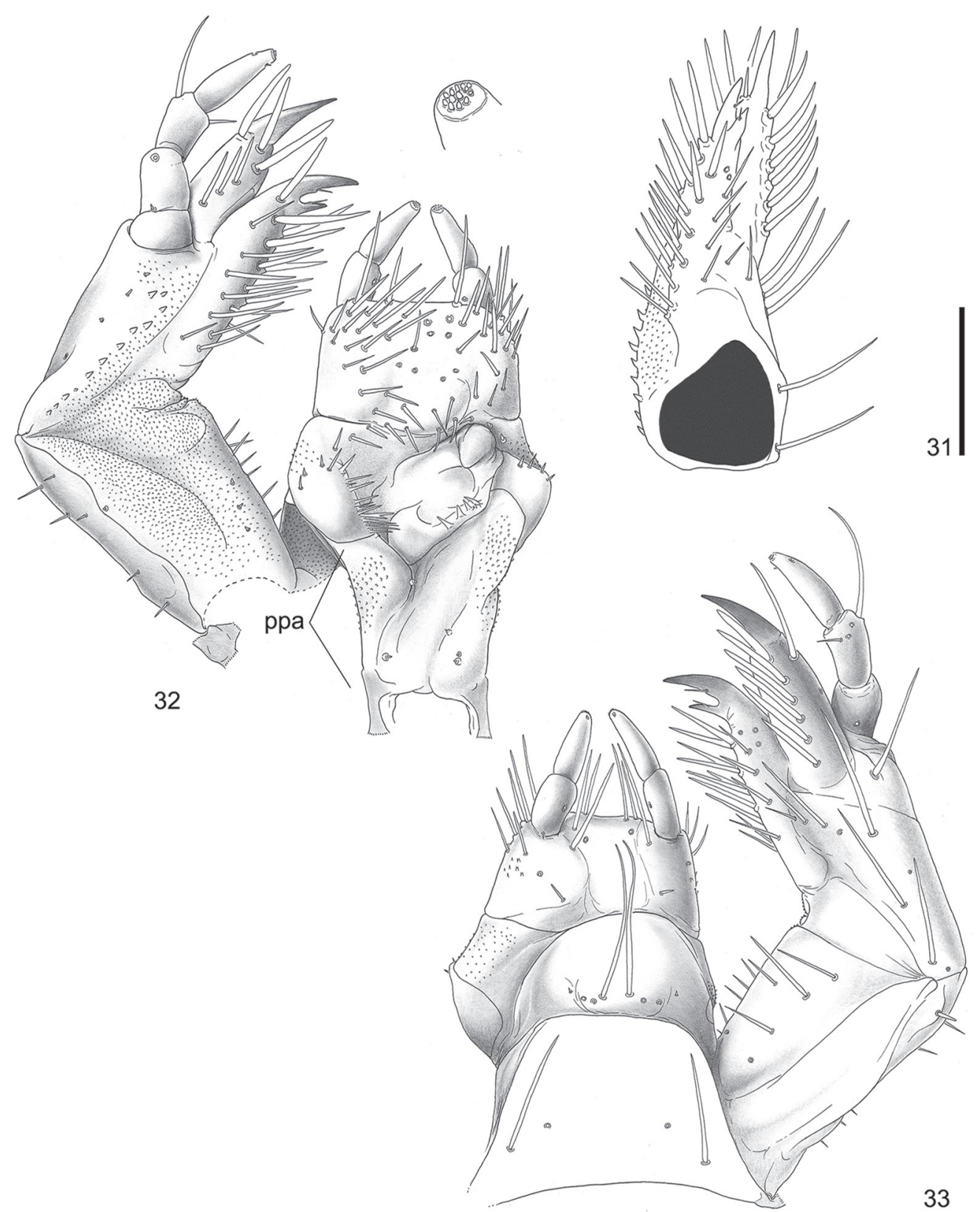

Figures 31-33. Paraegidium costalimai Vulcano, Pereira \& Martinez, 1966. Third-instar larva: (31) Left maxilla, inner (cardo omitted); (32) Maxilla, hypopharynx and ligula, dorsal; (33) Maxilla and labium, ventral. ppa = posterior preoral area. $S$ cale $=0.3 \mathrm{~mm}$ (palp details with magnification eight times bigger than the maxillolabial complex).

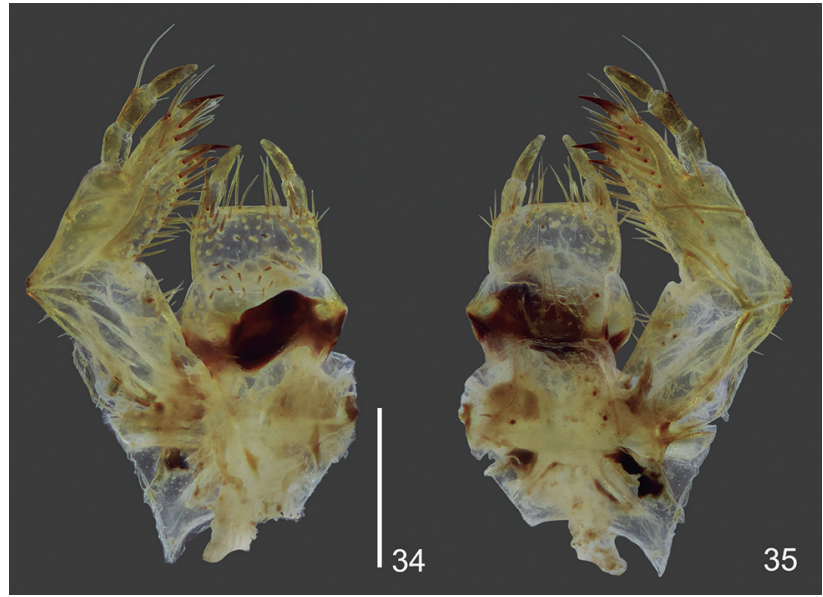

Figures 34-35. Paraegidium costalimai Vulcano, Pereira \& Martinez, 1966. Third-instar larva: (34) Maxilla, hypopharynx and ligula, dorsal; (35) Maxilla and labium, ventral. Scale $=0.5 \mathrm{~mm}$. lobe with 7-8 setae, pleural lobe with 3 setae, ventral anteromedial lobe with 7-8 setae, and ventral posterior lobe bare. Metathorax with pleural anterior and posterior lobes bearing a seta each, other lobes as mesothorax. Legs (Figs. 36-38) with trochanters bearing an anterior erect seta and a long posterior seta; pretarsus (Figs. 39-41) with 2 lateroventral setae and an acuminate apex, propretarsus longer than meso- and meso- longer than metapretarsus. Thoracic spiracle (Figs. 42-44, 74) with respiratory plate bearing oblong perforations, with 8 perforations in longitudinal radius and 4 perforations in ventral radius, and dorsal arm indistinct. Abdomen (Fig. 5, setation summarized in Table 2). Segment I-II with tergal anterior lobe bearing 6-10 setae, tergal medial lobe with 16-30 setae, tergal posterior lobe with 14-20 setae, pleural lobe with 1-4 setae, spiracular lobe with 3-5 setae, ventral anterior lobe with 8-10 setae, and ventral posterior lobe bare. Segment III with tergal anterior lobe bear- 
ing 12-16 setae, tergal medial lobe with $41-44$ setae, tergal posterior lobe with 11-15 thin setae and 11-14 stout setae, other lobes as segments I-II. Segments IV-V with tergal anterior lobe bearing 2-5 thin setae and 15 stout setae, tergal medial lobe with 21-26 thin setae and 28-29 stout setae, tergal posterior lobe with 2-4 thin setae and 25-26 stout setae, tergal lateral lobe with 1-2 setae, ventral anterior lobe with 4-6 setae, and other lobes as segments I-II. Segment VI with tergal posterior lobe bearing 19-20 thin setae, and other lobes as segments IV-V. Segment VII with tergal lobe bearing 62-64 setae, tergal lateral lobe with 0-1 seta, and dorsolateral and ventral lobes as segments IV-V. Segment VIII with a tergal lobe bearing 54-56 setae, pleural lobe with 1-4 setae, spiracular lobe with 1-2 setae, and ventral lobe with 4 setae. Segment IX with tergal lobe bearing 42-58 setae, pleural lobe with 6-9 setae, and ventral lobe with 4 setae. Segment $X$ (Figs. 54-55) with a sinuous anal opening and, and tergite with 98-110 thin setae. Spiracles (Figs. 45-48, 49-52) I-IV larger than V-VIII and C-shaped; respiratory plate I with 15 perforations in dorsal radius (DR), 13 perforations in longitudinal radius (LR), and 18

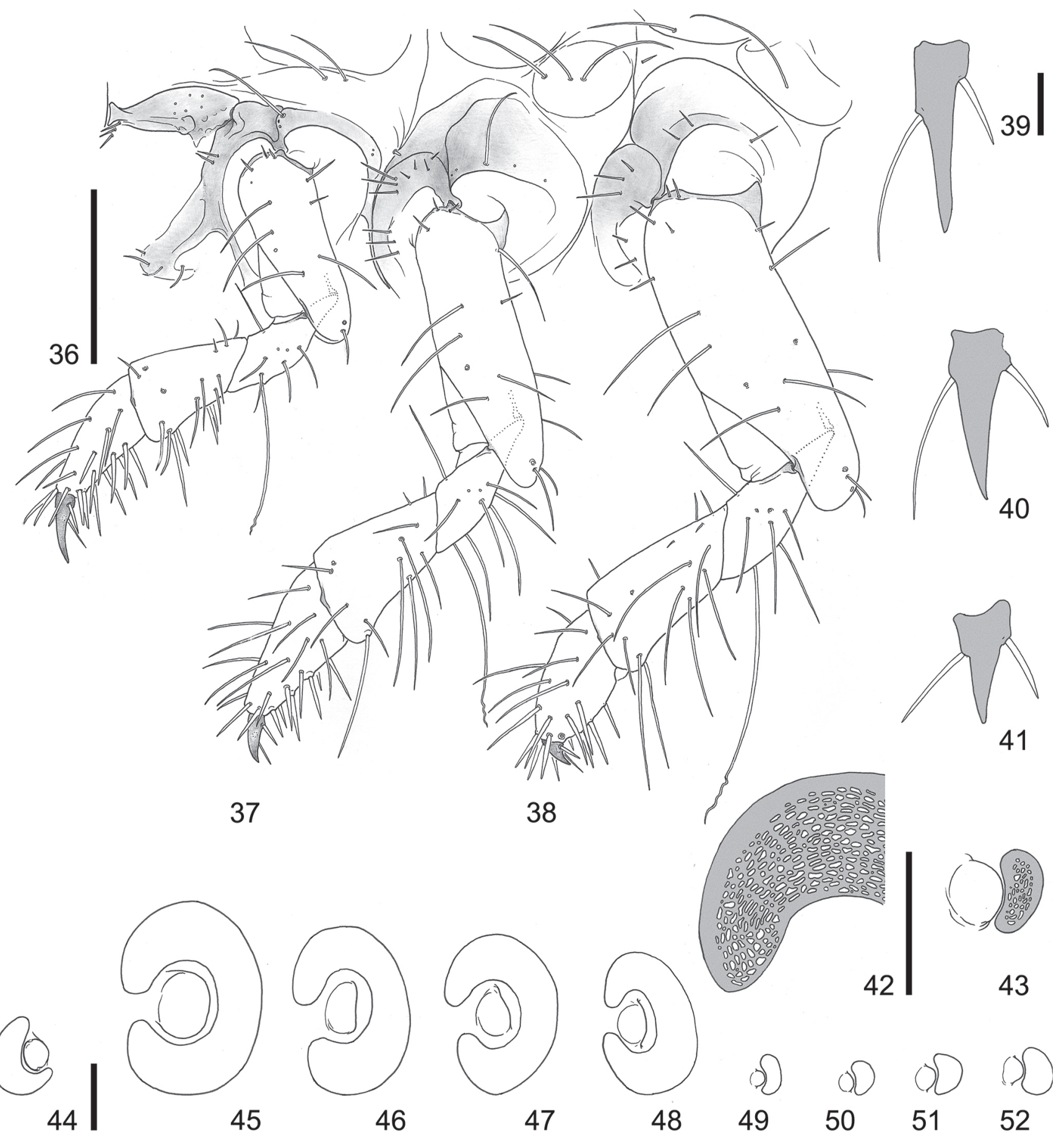

Figures 36-52. Paraegidium costalimai Vulcano, Pereira \& Martinez, 1966. Third-instar larva: (36-38) Left legs and pleurites (anterior, medial, posterior); (39-41) Left pro-, meso-, and metapretarsus, dorsal; (42) detail of dorsal arm of abdominal spiracle I; (43) Abdominal spiracle V; (44) Mesothoracic spiracle; (45-52) abdominal spiracle I-VIII. Scales: Figs. $36-38=0.5 \mathrm{~mm}$, Figs. $39-52=0.1 \mathrm{~mm}$. 


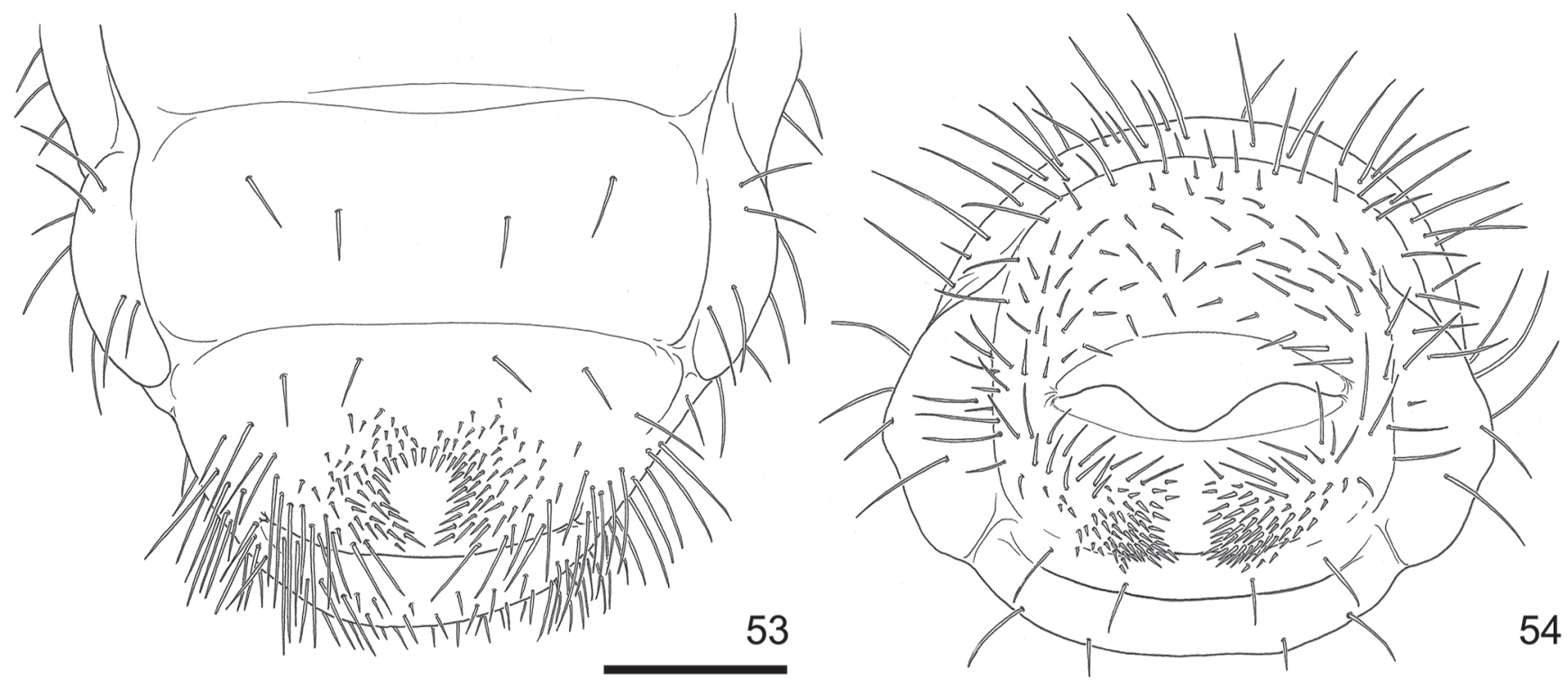

Figures 53-54. Paraegidium costalimaiVulcano, Pereira \& Martinez, 1966. Third-instarlarva: (53) Raster, ventral; (54) Abdominal segment X, posterior. Scale = $1 \mathrm{~mm}$.

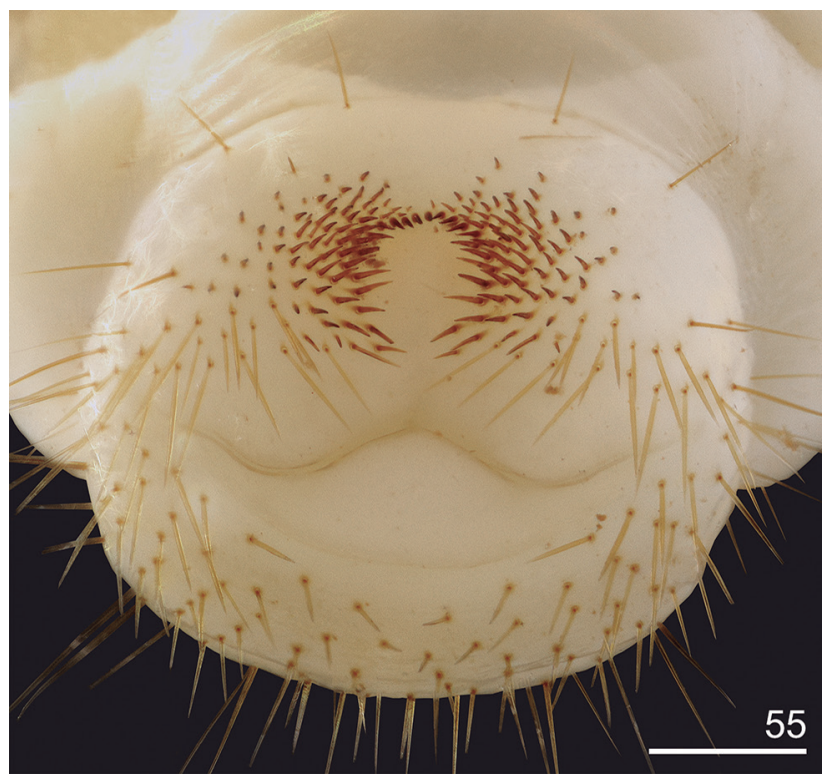

Figures 55. Paraegidium costalimai Vulcano, Pereira \& Martinez, 1966. Thirdinstar larva: abdominal segment $X$, posteroventral. Scale $=1 \mathrm{~mm}$.

perforations in ventral radius (VR); respiratory plates II-VI with 10-12 perforations in DR, 9-12 perforations in LR, and 11-15 perforations in VR; bulla I-IV slightly wider than the distances between respiratory plate arms; respiratory plates V-VIII with respiratory plate coma-like and with about 40 perforations. Raster (Figs. 53-55, setation in Table 1) with palidia not distinguished from tegilla, septula rounded; each side of tegillar area with 13-14 posterolateral thin setae, and 65-68 stout setae, of which 24-31 are preseptular setae; each side of campus with 2 setae. Anal lobes: dorsal lobe parabolic and bare, ventral lobes slightly defined, transverse, and bare.

Remarks: Including present contribution, six species of Orphninae have their third-instar larvae described, and all of them have a distinct epipharynx: pedium surrounded by heli, but Morón (1991) described A. cribratum larvae with pedium surrounded by pine-like setae. Some confusion and discordant interpretations were done regarding heli (fixed spine) and spine-like setae (see discussion in Albertoni et al., 2014) and the revision of material of $A$. cribratum is here emphasized to check the nature of the ornamentation that surround the pedium.

Other characters shared by Orphninae larvae are: antennomere IV with a dorsal and a ventral sensorial spot; ligula somewhat rectangular; raster with septula oval and palidia and tegillar setae barely differentiated from each other.

Larvae of $P$. costalimai are distinguished from other orphnine larvae by lacinia with 2 unci (Figs. 31-35) and abdominal spiracles I-IV distinctly larger than V-VIII (Figs. 45-52).

First-instar larva (Figs. 4, 62-72): like that of third instar above described, with following relative differences. Head (Figs. 4, 62-65) width about $0.7 \mathrm{~mm}$. Antennae (Fig. 64) with same sensilla pattern than the third instar, but segments relatively shortened. Epipharynx (Fig. 62) with right and left acanthoparia with 4-5 anterior setae and 5-6 minute posterior setae. Left molar bearing an acia with truncate apex and bearing a dense group of thin spines (Fig. 65). Hypopharynx (Fig. 63) with sclerite bearing about five right heli and about 7 left heli; phobae absent. Thorax. Metathoracic tergal lobe with a dorsolateral egg-buster on each side, egg-buster with a long and a minute backward directed spines, two conic upward-directed projections, a long seta, and a separated sclerite bearing projections (Fig. 71). Thoracic and abdominal spiracles (Figs. 66-70, 72) without bulla, abdominal respiratory plates I-IV (Figs. 67-68, 72) with anterior emargination, abdominal respiratory plates V-VIII (Figs. 69-70) with dorsal area smooth.

Remarks: The first and third-instar larvae are quite similar to each other as noted to other scarab beetles (e.g., Böving, 1936). However, the presence of egg-busters on the first instar can be useful to distinguish it from other instars as mentioned in some studies (e.g., Emden, 
1941; Šípek et al., 2008). Orphninae first-instar larvae are known only for Paraegidium costalimai (here described) and Chaetonyx robustus (illustrated by Gradinarov et al., 2015).

Pupa (Figs. 56-61): Body (Figs. 56-58) length about $9.1 \mathrm{~mm}$; thorax width about $3.5 \mathrm{~mm}$; white, integument macroscopically smooth and glabrous but covered by a thin and short microscopic pubescence, which gives a velvety appearance to the surface (magnification of 30x). Head (Fig. 59). Vertex is almost hidden under pronotum in dorsal view (Fig. 56). Epistomal suture and canthus indistinct. Clypeus trapezoid, male with lateral areas prominent (Fig. 59). Labrum transverse and triangular (Figs. 57-59). Maxillary palps prominent and somewhat triangular. Labium with a deep medial groove (Fig. 57). Antenna with three defined regions: scape-pedicel, funicle and clava. Thorax: Pronotum wider than long, great-
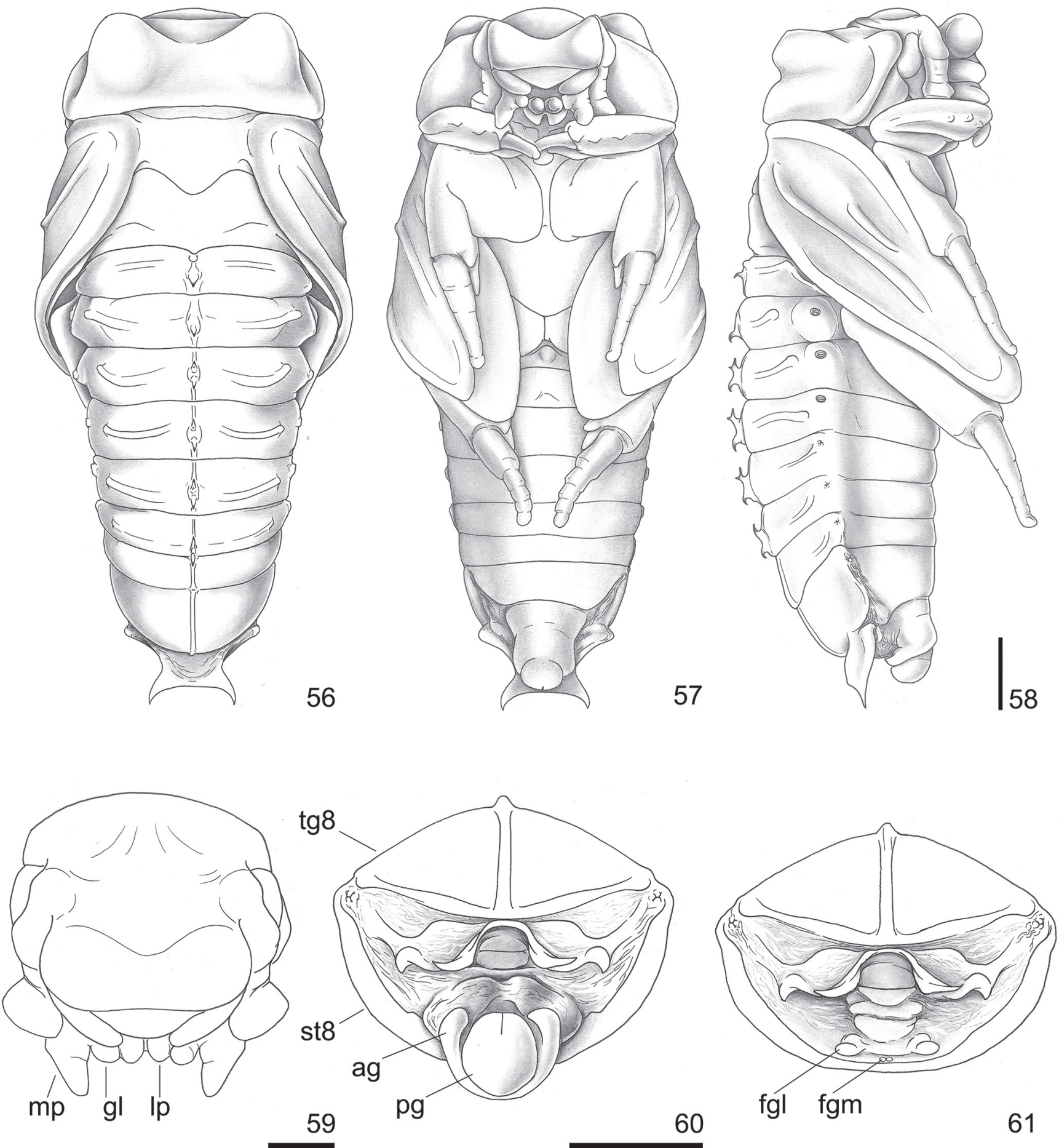

Figures 56-61. Paraegidium costalimai Vulcano, Pereira \& Martinez, 1966. Pupae: (56-58) Male (dorsal, ventral, lateral); (59) Head, male; (60) Male terminalia, posterior; (61) Female terminalia, posterior. $\mathbf{a g}=$ male anterior genital ampulla; $\mathbf{f g l}=$ female genital ampulla, posterolateral process; $\mathbf{f g m}=$ female genital ampulla, anteromedial tubercle; $\mathbf{g l}=$ galea; $\mathbf{l} \mathbf{p}=$ labial palp; $\mathbf{m p}=$ maxillary palp; $\mathbf{p g}=$ male posterior genital ampulla; $\mathbf{s t} \mathbf{8}=$ abdominal sternite VIII; $\mathbf{t g} \mathbf{8}=$ abdominal tergite VIII. Scale $=1 \mathrm{~mm}$. 
est width at posterior margin, lateral margins rounded, males with a pair of large semispherical tubercles. Prosternum with posterior process rounded. Pronotum seeming longer than mesonotum, and mesonotum longer than metanotum in dorsal view (Fig. 56). Elytra curved ventrally around the body and with raised longitudinal carinae. Pro-, meso- and metacoxa contiguous; femur-tibia slightly exposed in prothorax and exposed in metathorax; protibia with three outer tubercle-like teeth; meso- and metatibia with 2 tubercle-like spurs, posterior spur at least twice longer than anterior spur; metatarsus with tarsomere I as long as other tarsomeres combined, or almost so. Mesothoracic spiracle present in a cavity between the pronotum, elytron and anterior and medial legs. Abdomen: Gin traps (dioneiform organs sensu Costa et al., 1988) absent, tergites I-II with a dorsal spine, III-V with three spines (anterior, dorsal, posterior), VI with two spines (anterior, posterior); VII-VIII with a longitudinal carina; I-VII with laterodorsally transverse carina. Abdominal spiracles I-IV with peritreme, I hidden under the wings, V-VIII as cuticular invagination; urogomphi present. Male terminalia (Fig. 60). Proximal genital ampulla divided in a cylindrical anterior area (phallobasis) and a posterior area bearing two dorsal spines (parameres); posterior ampulla semispherical and with a distal impressed line; sternite $X$ hidden in ventral view. Female terminalia (Fig. 61). Sternite IX with genital ampulla formed by two parts, an anteromedial pair of small tubercles, and a posterolateral pair of prominent processes (see remarks); tergite $X$ ventrally exposed as a membranous lobe.

Remarks: The pupae are known to Orphninae species: A. cribratum (described by Morón, 1991), C. robustus (figured and measured by Gradinarov et al., 2015), and P. costalimai (here described). All three species have urogomphi, abdominal tergites I-VI with medial projection bearing hook-like acute spines, abdominal tergites VII-VIII with longitudinal carina, and abdomen without gin traps. Each medial projection of abdominal tergite I-VI has one spine in C. robustus, two spines in A. cribratum, and one spine (abdominal segments I-II), two (VI), or

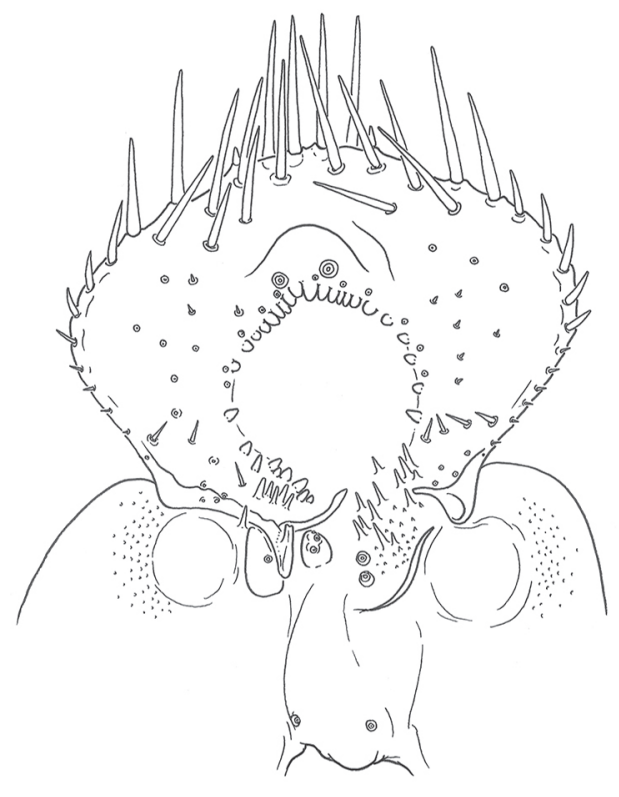

62

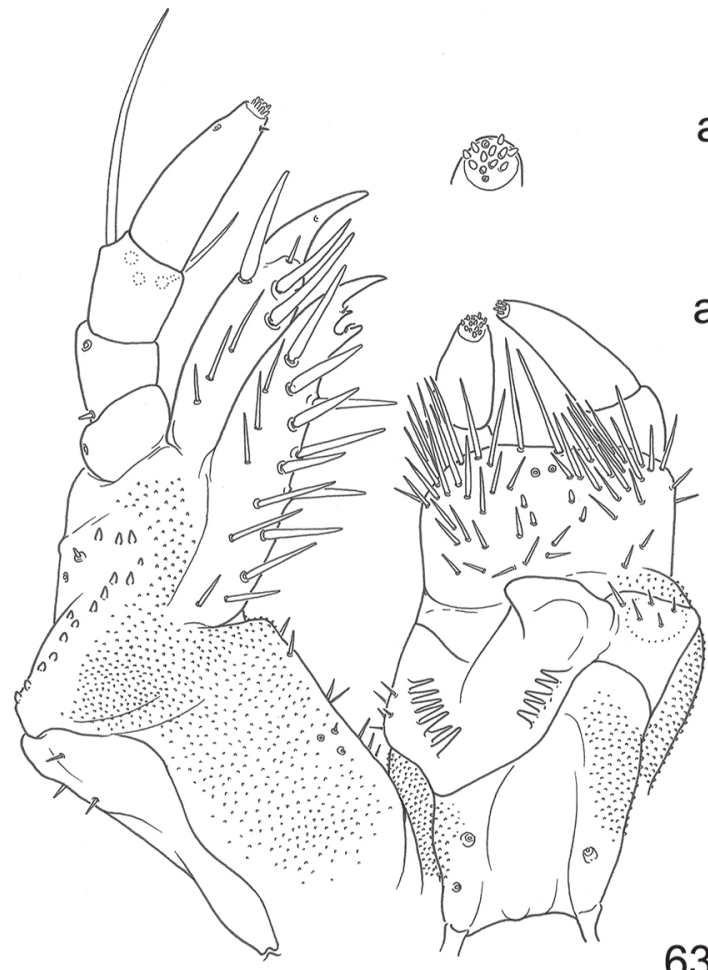

63

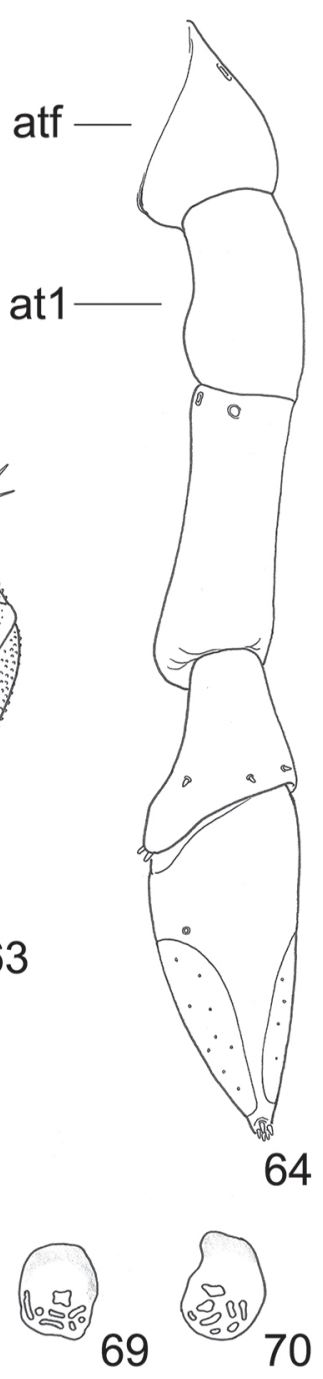

Figures 62-70. Paraegidium costalimai Vulcano, Pereira \& Martinez, 1966. First-instar larva: (62) Epipharynx; (63) Maxilla, hypopharynx and ligula, dorsal; (64) Left antenna, inner; (65) Acia of right mandible, ventral; (66) Mesothoracic spiracle; (67-70) Abdominal spiracles I-II, and V-VI. atf = antennifer; at1 = antennomere I. $\mathrm{Scale}=0.1 \mathrm{~mm}$ (palp details with magnification eight times bigger than the maxillolabial complex). 
three spines (III-V) in P. costalimai. Other diagnostic characters to $P$. costalimai are (opposition to A. cribratum in parentheses): abdomen without prominent pleural lobes (tergites II-VII with pleural lobes prominent and covered with conspicuous minute pubescence), longitudinal ca- rina of abdominal tergite VII smooth (carina serrate). The description of pupa of $C$. robustus is needed to clarify its morphology.

Female pupae of $A$. cribratum and $P$. costalimai have genital ampullae with two parts: an anteromedial pair
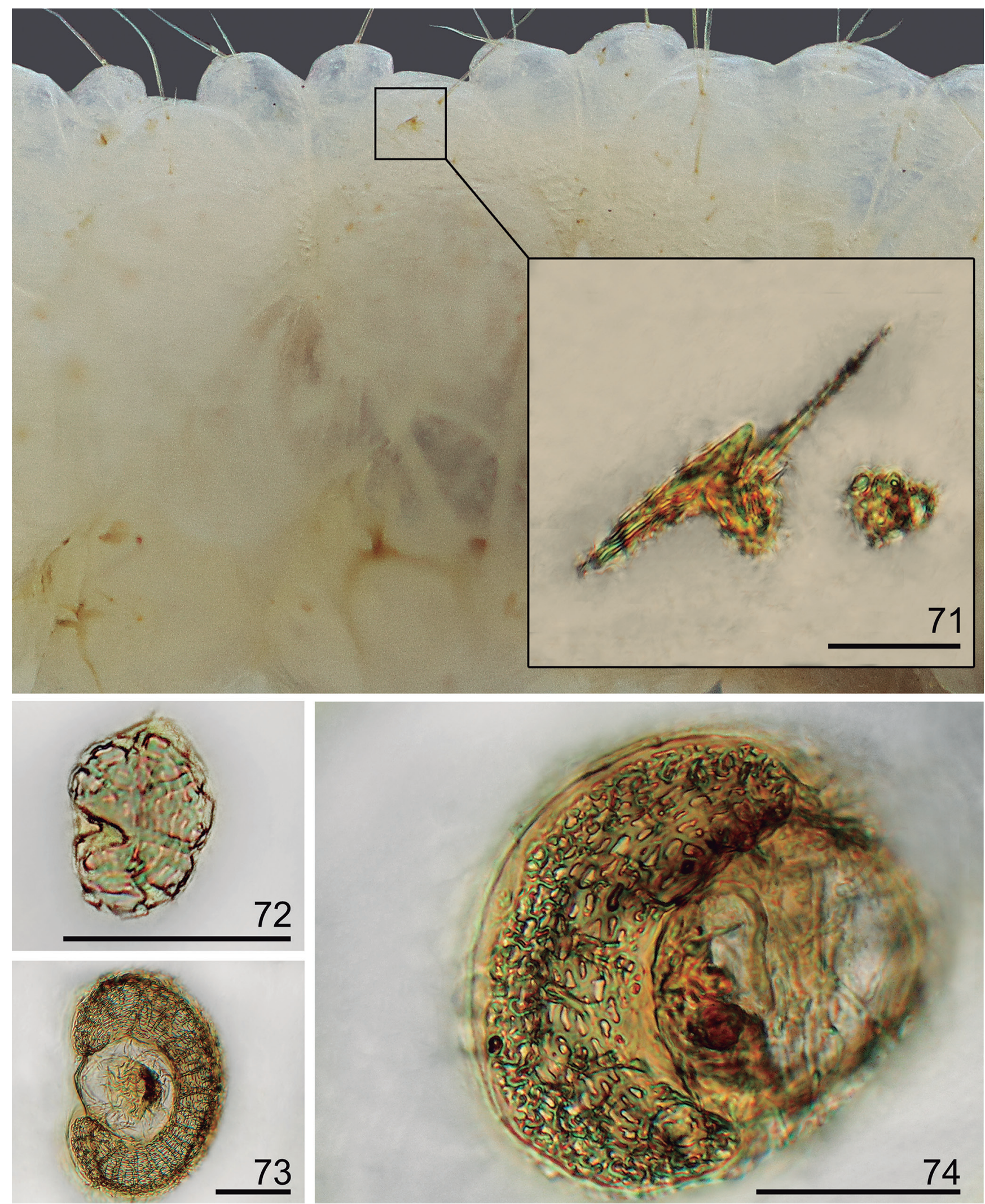

Figures 71-74. Paraegidium costalimai Vulcano, Pereira \& Martinez, 1966. Larvae: (71-72) First instar; (73-74) Third instar; (71) Egg-buster, laterodorsal; (72-73) Abdominal spiracle l; (74) Mesothoracic spiracle. Scales: Fig. $71=0.01 \mathrm{~mm}$, Figs. $72-74=0.1 \mathrm{~mm}$. 
of small tubercles and a posterolateral pair of prominent finger-like processes. The small tubercles are found in other Scarabaeidae pupae, but the finger-like processes are only observed in Orphninae (see Morón, 1991, 1993; Sousa et al., 2018). Morón (1991) showed that these finger-like processes are related to the gonostyli of adult females.

\section{Key to third instar of Orphninae known larvae}

1 Epipharynx without plegmatia and corypha not prominent; lacinia with 1 or 2 unci (never with 3 tips); posterior area of ligula with thin setae; anal slit sinuate (Aegidiini)

- Epipharynx with plegmatia and corypha anteriorly prominent; lacinia with 3 unci (or 1 tridentate uncus); posterior area of ligula with stout setae, these setae are distinctly wider than anterior setae; anal slit Y-shaped (Orphnini).

2 Lacinia with 1 uncus; abdominal spiracles decreasing progressively in diameter posteriorly; metapretarsus with rounded and reduced apex (Mexico) Aegidium cribratum Bates, 1887

- Lacinia with 2 unci (Figs. 31-35); abdominal spiracles I-IV distinctly larger than V-VIII (Figs. 45-52); metapretarsus with well-developed and acuminated apex (Figs. 38, 41) (Brazil)

Paraegidium costalimai Vulcano et al., 1966

3 Surface of labrum without transverse carinae; stridulatory area of stipes with 14-15 acute teeth

....4

- Surface of labrum with two transverse carinae; stridulatory area of stipes with 20 acute teeth (Hybalus)..

4 Surface of labrum not trilobate and with small tubercles irregularly distributed (Italy)...............Chaetonyx robustus liguricus Mariani, 1946

- Surface of labrum trilobate and without irregular distributed tubercles (Madagascar) ................................ Triodontus nitidulus (Guérin, 1844)

5 Clypeus with two externoclypeal setae; apex of galea with 2-3 setae distinctly larger than outer setae; hypopharyngeal sclerome tridentate (Italy). H. benoiti Tournier, 1864

- Clypeus with one externoclypeal seta; apex of galea with similar shaped setae; hypopharyngeal sclerome bidentate (Morocco)... .. H. rotrouni Petrovitz, 1964

\section{DISCUSSION}

\section{Egg-buster or egg-hatching structure of the first-instar larvae}

The embryo of many insects has spines which aid the rupture of the chorion during hatching. These have been called hatching spines, oviruptors, or egg-busters (Hayes, 1929). With the aid of muscular contractions, the egg-busters assist the embryo to break the chorion during the hatching process (Vitner \& Král, 2009). Besides the function of egg-busters, some authors showed that the structure is also useful to identify some first-instar Coleoptera larvae (e.g., Scarabaeidae, Emden, 1941; Šípek et al., 2008).

Egg-hatching structure was first described in Scarabaeoidea by Rittershaus (1925: figs. 1-4; 1927: figs. 133-143) in two European species of Rutelinae (Anomala aenea Della Beffa, 1910; Phyllopertha horticula
(Linnaeus, 1758)). This author described the structure as a triangular and sclerotized spine present on each dorsolateral side of metathorax. Afterwards, Gray et al. (1947) studied the embryo and the hatching process of $P$. hortic$u l a$, and noted the egg-busters.

Hayes (1929) did not found egg-busters in the first-instar larvae of several Scarabaeidae species, and indicated that some stiff dorsal setae probably aid the insect somehow to burst the egg chorion. The author added that the mandibles possibly also aid the hatching process.

Some studies have been reporting the presence of egg-busters with variable shapes in some Scarabaeidae species. Gardner (1935) found egg-busters in Rutelinae (Anomala polita Blanchard, 1851) and Cetoniinae (Heterorrhina elegans (Fabricius, 1781) and Oxycetonia albopunctata (Fabricius, 1798)), but Fidler (1936) did not find this structure in Melolonthinae (Amphimallon solstitialis (Linnaeus, 1758), Melolontha melolontha (Linnaeus, 1758), and Serica brunnea (Linnaeus, 1758)).

Vitner \& Král (2009) in a study of immatures of Synapsis yunnanus Arrow, 1933 (Scarabaeinae) suggested that egg-busters may not always be responsible for the initial fracture of chorion and that these sclerites possibly have a supportive function. The authors noted that the egg-busters probably serve as mechanoreceptors, since the sclerotized insertions of setae of the egg-busters keep them in a constant position relative to the chorion.

The shape and the organization of egg-busters in scarab beetles are similar to each other, consisting of long and sclerotized projection backward directed (eventually described as spine-like projection, conical projection or peg-like projection), with a long seta near to median area. This shape was reported in several works, mainly on Cetoniinae first-instar larvae: Neoscelis dohrni (Westwood, 1855) (described by Nogueira et al., 2004), Dicronocephalus wallichi bourgoini Pouillaude, 1914 (described by Šípek et al., 2008), and Homothyrea inornatipennis Gahan, 1903 (described by Šípek et al., 2012); but also to melolonthine Propomacrus bimucronatus (Pallas, 1781 ) and P. cypriacus Alexis \& Markis, 2002 (described by Šípek et al., 2011).

The shape of egg busters in other scarab beetles can be different from the above-mentioned. The egg-buster of the dung beetle Synapsis yunnanus (Scarabaeinae, described by Vitner \& Král, 2009) has three conical projections backward directed, each projection bearing one robust subdistal seta. However, the egg-busters of $P$. costalimai are composed of a backward directed spine and other two small conic upward-directed projection, and a separated sclerite bearing projections. The presence of a separated sclerite was not reported in any of the works cited above.

Studies on the egg-busters and their function are very scarce in most families of Scarabaeoidea. Additional data on the functional morphology of this structure can help us to understand better the behavior and biology of these animals. Also, it can provide important information for taxonomy, systematics and cladistics. 


\section{ACKNOWLEDGMENTS}

RS thanks Coordenação de Aperfeiçoamento de Pessoal de Nível Superior (proc.: CAPES código financeiro 001) for grant support. We thank Dr. Sônia A. Casari (MZSP) for supervision, Dione Seripierri, Gustavo Rizzi, and Marta Zamana (Library of Museu de Zoologia da Universidade de São Paulo) for providing indispensable bibliographic references of difficult access for the development of this study. To Dr. Gabriel Biffi and Dr. Sônia Casari for inviting us to submit this manuscript in celebration of the $80^{\text {th }}$ anniversary of Dr. Cleide Costa, who significantly contributed to the knowledge of morphology and biology of immature Coleoptera.

\section{REFERENCES}

Albertoni, F.F.; Fuhrmann, J. \& Ide, S. 2014. Lagochile emarginata (Gyllenhal): morphology of immature and imago, and biological records (Coleoptera, Scarabaeidae, Rutelinae). Revista Brasileira de Entomologia, 58: 32-46. D0I

Barbero, E. \& Palestrini, C. 1993. Chaetonyx robustus spp. liguricus Mariani, 1946: Descrizione del terzo stadio larvale e note sulla morfologia preimmaginale della famiglia (Coeloptera: Scarabaeoidea: Orphinidae). Bollettino della Società Entomologica Italiana, 125: 143-149.

Böving, A.G. 1936. Description of the larva of Plectris aliena Chapin and explanation of new terms applied to the epipharynx and raster. Proceedings of the Entomological Society of Washington, 38: 169-185.

Burrows, R.B. 1965. Miscellaneous Helminth Technics. In: Burrows, R.B. 1965. Microscopic diagnosis of the parasites of man. New Haven, Yale University Press. p. 69-93.

Costa, C.; Vanin, S.A. \& Casari, S.A. 1988. Larvas de Coleoptera do Brasil. São Paulo, Museu de Zoologia da Universidade de São Paulo. 282p., 165 pls.

Emden, F.I. van. 1941. Larvae of British beetles II. A key to the British Lamellicornia larvae. Entomologist's Monthly Magazine, 77: 117-127, 181-192.

Fidler, J.H. 1936. Some notes on the morphology of the immature stages of some British chafer beetles. Annals of Applied Biology, 23: 114-132. DOI

Frolov, A.V. 2012. Diagnosis, classification, and phylogenetic relationships of the orphnine scarab beetles (Coleoptera, Scarabaeidae: Orphninae). Entomologicheskoe Obozrenie, 91: 332-351. [in Russian, English version in: Entomological Review, 92: 782-797. D01

Frolov, A.V. \& Vaz-de-Mello, F.Z. 2015. A new genus and species of Orphninae (Coleoptera: Scarabaeidae) associated with epiphytes in an Andean cloud forest in Ecuador. Zootaxa, 4007: 433-436. DOI

Frolov, A.V.; Akhmetova, L.A. \& Vaz-de-Mello, F.Z. 2017a. Revision of the South American genus Paraegidium Vulcano et al. (Coleoptera: Scarabaeidae: Orphninae). Journal of Natural History, 51(17-18): 995-1014. D01

Frolov, A.V.; Akhmetova, L.A. \& Vaz-de-Mello, F.Z. 2017b. Revision of the mainland species of the neotropical genus Aegidium Westwood (Coleoptera: Scarabaeidae: Orphninae). Journal of Natural History, 51(19-20): 1035-1090. DOI

Frolov, A.V.; Akhmetova, L.A. \& Vaz-de-Mello, F.Z. 2019. Contribution to the knowledge of the Neotropical canopy dwelling genus Onorius (Coleoptera, Scarabaeidae, Orphninae): another species from southern Ecuador and notes on the hind gut morphology in the Orphninae. Journal of Natural History, 53: 17-18. D0I

Frolov, A.V.; Montreuil, 0.\& Akhmetova, L.A. 2016. Review of the Madagascan Orphninae (Coleoptera: Scarabaeidae) with a revision of the genus Triodontus Westwood. Zootaxa, 4207: 1-93. D01
Gardner, J.C.M. 1935. Immature stages of Indian Coleoptera (Scarabaeoidea). Indian Forest Records, 1: 1-33 + 4 pls.

Gradinarov, D. 2014. Chaetonyx robustus (Scarabaeidae: Orphninae) - new natural host of Heterorhabditis bacteriophora (Rhabditida: Heterorhabditidae). ZooNotes, 57: 1-4.

Gradinarov, D. \& Petrova, Y. 2012. Development of Steinernema feltiae (Rhabditida: Steinernematidae) in larvae of Chaetonyx robustus (Coleoptera: Orphnidae). ZooNotes, 36: 1-4.

Gradinarov, D.; Petrova, Y.; Tasheva-Terzieva, E. \& Frolov, A.V. 2015. Biology of the blind geobiont scarab beetle genus Chaetonyx Schaum, 1862 (Scarabaeidae: Orphninae) with new distribution records of Ch. robustus Schaum, 1862 from Bulgaria. ZooNotes, 81: 1-14.

Gray, R.A.H.; Peet, W.V. \& Rogerson, J.P. 1947. Observations on the chafer grub problem in the Lake District. Bulletin of Entomological Research, 37(3): 455-468. D0I

Hayes, W.P. 1929. Morphology, taxonomy, and biology of larval Scarabaeoidea. Illinois Biological Monographs, 12: 1-125. DOI

Johansen, D.A. 1940. The Glycerin Method. In: Johansen, D.A. 1940. Plant Microtechnique. New York, McGraw-Hill Book Co. Inc. p.119-120.

Kawada, R. \& Buffington, M.L. 2016. A scalable and modular dome illumination system for scientific microphotography on a budget. PLOS ONE, 11: e0153426 [20 p]. D0I

Lawrence, J.F. 1991. Larval morphology. In:Stehr, F.W. (Ed.). Immature Insects, Dubuque, Kendall/Hunt Publishing Company. v. 2, p.146-177.

Morón, M.A. 1991. Larva and pupa of Aegidium cribratum Bates (Coleoptera: Scarabaeidae: Orphninae). The Coleopterists Bulletin, 45(4): 360-367.

Morón, M.A. 1993. Observaciones comparativas sobre la morfología pupal de los Coleoptera Melolonthidae neotropicales. Giornale Italiano di Entomologia, 6(33): 249-255.

Nogueira, G.; Morón, M.A.; Fierros-López, H.E. \& Navarrete-Heredia, J.L. 2004. The immature stages of Neoscelis dohrni (Westwood) (Coleoptera: Scarabaeidae: (etoniinae: Goliathini) with notes on adult behavior. The Coleopterists Bulletin, 58: 171-183. DOI

Paulian, R. \& Lumaret, J.-P. 1982. La larve des Orphnidae (Col. Scarabaeoidea). Bulletin de la Société Entomologique de France, 87: 263-272.

Perina, G. \& Camacho, A.I. 2016. Permanent slides for morphological studies of small crustaceans: Serban's method and its variation applied on Bathynellace (Malacostraca). Crustaceana, 89(10): 1161-1173. D0I

Randriamanantsoa, R.; Aberlenc, H.-P.; Ralisoa, 0.B.; Ratnadass, A. \& Vercambre, B. 2011. Les larves des Scarabaeoidea (Insecta, Coleoptera) en riziculture pluviale des régions de haute et moyenne altitudes du Centre de Madagascar. Zoosystema, 32: 19-72.

Ritcher, P.0. 1966. White grubs and their allies. A study of North American scarabaeoid larvae. Corvalis, Oregon State University Press. 219p. (Oregon State monographs, Studies in entomology, n.4).

Rittershaus, K. 1925. Eine neue Art von Eisprengern bei Lamellicornienlarven (Phyllopertha horticola L. und Anomala aenea Deg.). Biologischer Anzeiger, 62: 31-33.

Rittershaus, K. 1927. Studien zur morphologie und biologie von Phyllopertha horticola L. und Anomala aenea Geer. (Coleopt.). Zeitschrift für Morphologie und Ökologie der Tiere, 8(3-4): 271-408. https://link. springer.com/article/10.1007/BF00407447.

Rodrigues, S.R.; Barbosa, C.A.F.; Fuhrmann, J. \& Amaro, R.A. 2018. Mating behavior and description of immature stages of (yclocephala melanocephala (Fabricius, 1775) (Coleoptera: Scarabaeidae: Dynastinae), identification key and remarks on known immatures of Cyclocephalini species. Revista Brasileira de Entomologia, 62: 205-219. D0I

Rojkoff, S. \& Frolov, A. 2016. Révision des espèces du genre Aegidium Westwood, 1845, des Petites Antilles (Coleoptera: Scarabaeidae, 
Orphninae, Aegidiini). Annales de la Société Entomologique de France (N.S.), 52(6): 354-368. DOI

Sawada, H. 1991. Morphological and phylogenetical study on the larvae of pleurostict Lamellicornia in Japan. Tokyo, Tokyo University of Agriculture Press.

Šípek, P.; Janšta, P. \& Král, D. 2011. Immature stages of Euchirinae (Coleoptera: Scarabaeoidea): genera Cheirotonus and Propomacrus with comments on their phylogeny based on larval and adult characters. Invertebrate Systematics, 25(4): 282-302. D01

Šípek, P.; Janšta, P. \& Král, D. 2012. Homothyrea inornatipennis (Coleoptera: Scarabaeidae: Cetoniinae: Leucocelina): immature stages and distribution. Acta Entomologica Musei Nationalis Pragae, 52 (Suppl. 2): 183-193.

Šípek, P.; Král, D. \& Jahn, 0. 2008. Description of the larvae of Dicronocephalus wallichi bourgoini (Coleoptera: Scarabaeidae: Cetoniinae) with observations on nesting behavior and life cycle of two Dicronocephalus species under laboratory conditions. Annales de la Société entomologique de France, (N.S.), 44(4): 409-417. D01

Sousa, R.; Fuhrmann, J.; Kouklík, 0. \& Šípek, P. 2018. Immature stages of three species of Inca LePeletier \& Serville, 1828 (Coleoptera: Scarabaeidae: (etoniinae) and morphology of phytophagous scarab beetle pupa. Zootaxa, 4434: 65-88. D01

Vitner, J. \& Král, D. 2009. Immature stages and nest construction in Synapsis yunnanus (Coleoptera: Scarabaeidae). Annales de la Société entomologique de France, (N.S.), 45: 49-66. D0I

Vulcano, M.A.; Pereira, F.S. \& Martínez, A. 1966. Notas sobre Orphninae neotrópicos com descrição de um gênero e uma espécie novos (Coleoptera). Papéis Avulsos de Zoologia, 18(22): 251-260.

Widden, P. 2001. The use of glycerin jelly for mounting stained roots for the observation and quantification of endomycorrhizal fungi. Mycologia, 93: 1026-1027. 